A Research Report for Rockwell Hanford Operations

\title{
Distribution of Polychlorinated Biphenyls (PCBs) in Surface Sediments of Gable Mountain Pond
}

R. G. Riley

L. A. Prohammer

D. A. Neitzel

R. M. Bean

J. M. Thomas

January 1986

Prepared for the U.S. Department of Energy under Contract DE-AC06-76RLO 1830

Pacific Northwest Laboratory Operated for the U.S. Department of Energy by Battelle Memorial Institute 


\title{
DISCLAIMER
}

This report was prepared as an account of work sponsored by an agency of the United States Government. Neither the United States Government nor any agency thereof, nor any of their employees, makes any warranty, express or implied, or assumes any legal liability or responsibility for the accuracy, completeness, or usefulness of any information, apparatus, product, or process disclosed, or represents that its use would not infringe privately owned rights. Reference herein to any specific commercial product, process, or service by trade name, trademark, manufacturer, or otherwise, does not necessarily constitute or imply its endorsement, recommendation, or favoring by the United States Government or any agency thereof. The views and opinions of authors expressed herein do not necessarily state or reflect those of the United States Government or any agency thereof.

\author{
PACIFIC NORTHWEST LABORATORY \\ operated by \\ BATTELLE \\ for the \\ UNITED STATES DEPARTMENT OF ENERGY \\ under Contract DE-AC06-76RLO 1830
}

\begin{tabular}{|c|c|}
\hline \multicolumn{2}{|c|}{ Printed in the United States of America } \\
\hline \multicolumn{2}{|c|}{ Available from } \\
\hline \multicolumn{2}{|c|}{$\begin{array}{l}\text { National Technical Information Service } \\
\text { United States Department of Commerce }\end{array}$} \\
\hline \multicolumn{2}{|c|}{5285 Port Royal Road } \\
\hline \multicolumn{2}{|c|}{ Springfield, Virginia 22161} \\
\hline \multirow{2}{*}{\multicolumn{2}{|c|}{$\begin{array}{l}\text { NTIS Price Codes } \\
\text { Microfiche } \mathrm{A} 01\end{array}$}} \\
\hline & \\
\hline \multicolumn{2}{|c|}{ Printed Copy } \\
\hline & Price \\
\hline Pages & Codes \\
\hline 001-025 & $\mathrm{A} 02$ \\
\hline 026-050 & $\mathrm{A} 03$ \\
\hline 051-075 & A04 \\
\hline $076-100$ & A05 \\
\hline $101-125$ & A06 \\
\hline $126-150$ & $\mathrm{~A} 07$ \\
\hline $151-175$ & A08 \\
\hline $176-200$ & A09 \\
\hline $201-225$ & $\mathrm{~A} 010$ \\
\hline $226-250$ & A011 \\
\hline $251-275$ & $\mathrm{~A} 012$ \\
\hline $276-300$ & $\mathrm{~A} 013$ \\
\hline
\end{tabular}


A RESEARCH REPORT FOR ROCKWELL HANFORD OPERATIONS

DISTRIBUTION OF POLYCHLORINATED

BIPHENYLS (PCBS) IN SURFACE

SEDIMENTS OF GABLE MOUNTAIN POND

R. G. Riley

L. A. Prohammer

D. A. Neitzel

R. M. Bean

J. M. Thomas

January 1986

Prepared for

the U.S. Department of Energy

under Contract DE-AC06-76RLO 1830

Pacific Northwest Laboratory

Richland, Washington 99352 

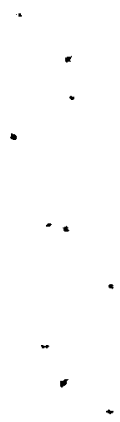

$\vdots$ 


\section{SUMMARY}

In June of 1984, samples of sediments were collected and anaryzed to determine the concentration and distribution of polychlorinated biphenyls (PCBS) in Gable Mountain Pond, which is located on the Hanford Site in southeastern Washington State. This work was initiated in response to a need for information in support of proper stabilization and/or waste management decisions for the pond, taking into account current federal regulations governing the disposal of PCB-containing wastes.

All samples, with one exception, were found to contain the specific PCB Arocior 1260, a constituent of the insulating fluid used in electric utility transformers. The highest concentration of PCBs in the pond was found next to the mouth of the inlet pipe. The distribution of PCBs over the pond is consistent with the hypothesis that they entered primarily through the inlet pipe and spread along the length of the pond in a roughly westerly direction. Concentrations of Arochlor 1260 ranged from 2 to 148 parts per billion, which is roughly two to four orders of magnitude below the regulated upper concentration limit (50 parts per million) for the disposal of PCB-contaminated waste. 


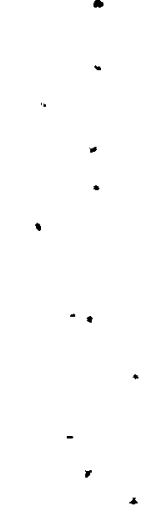

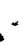




\section{ACKNOWLEDGMENTS}

This work was supported by the U.S. Department of Energy under the auspices of the Waste Management Program Office of Rockwell Hanford Operations. We wish to thank A. J. Scott, C. S. Abernethy, R. W. Hanf, Jr., E. W. Lusty, and B. L. Thomas for their excellent field and laboratory assistance on this project. 


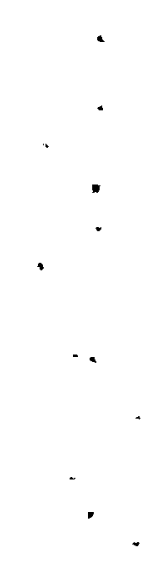


ACKNOWLEDGMENTS $\ldots \ldots \ldots \ldots \ldots \ldots \ldots \ldots \ldots \ldots \ldots \ldots \ldots \ldots \ldots \ldots \ldots \ldots \ldots \ldots \ldots$

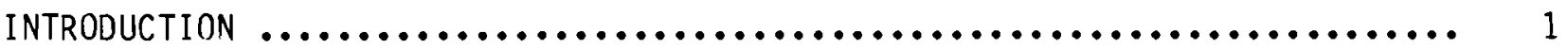

STRATEGY FOR SURVEYS $\ldots \ldots \ldots \ldots \ldots \ldots \ldots \ldots \ldots \ldots \ldots \ldots \ldots \ldots \ldots \ldots \ldots \ldots \ldots \ldots \ldots$

PHASE I: PRELIMINARY SURVEY $\ldots \ldots \ldots \ldots \ldots \ldots \ldots \ldots \ldots \ldots \ldots \ldots \ldots \ldots \ldots \ldots$

PHASE II: COMPREHENSIVE COLLECTION AND CHEMICAL

ANALYSIS OF SEDIMENT SAMPLES $\ldots \ldots \ldots \ldots \ldots \ldots \ldots \ldots \ldots \ldots \ldots . . \ldots 9$

RESULTS $\quad \ldots \ldots \ldots \ldots \ldots \ldots \ldots \ldots \ldots \ldots \ldots \ldots \ldots \ldots \ldots \ldots \ldots \ldots \ldots \ldots \ldots \ldots \ldots \ldots$

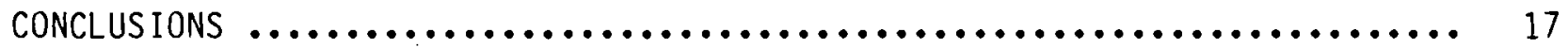

REFERENCES

APPENDIX A: SURVEY METHODS $\ldots \ldots \ldots \ldots \ldots \ldots \ldots \ldots \ldots \ldots \ldots \ldots \ldots \ldots \ldots \ldots \ldots \ldots \ldots$

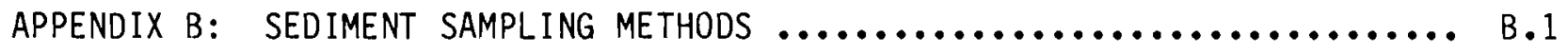

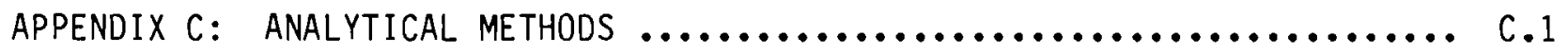

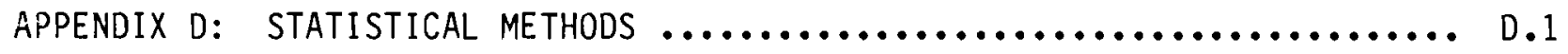




\section{FIGURES}

1 Map of the Hanford Site $\ldots \ldots \ldots \ldots \ldots \ldots \ldots \ldots \ldots \ldots \ldots \ldots \ldots \ldots \ldots \ldots \ldots \ldots$

2 Biphenyl Structure and Numbering of Carbon Atoms in

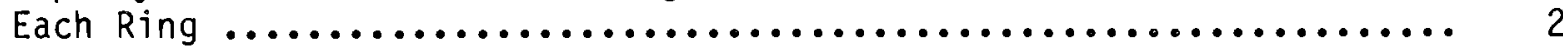

3 Gable Mountain Pond $\ldots \ldots \ldots \ldots \ldots \ldots \ldots \ldots \ldots \ldots \ldots \ldots \ldots \ldots \ldots \ldots \ldots \ldots$

4 Placement of Transects in Gable Mountain Pond ................. 8

5 Locations of All Samples Taken from Gable Mountain

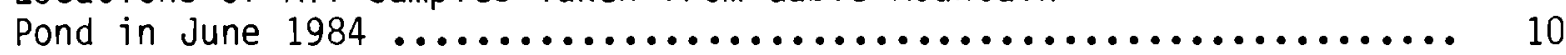

6 Gas Chromatograph Peaks of Aroclor 1260, Used in the

Quantification of Total PCBs Contained in

Environmental Samples

7 Observed PCB Concentrations in Gable Mountain Pond

Sediments

8 Contour Map Indicating Predicted Concentration of

PCBs in Gable Mountain Pond Sediments ...................... 16

A.1 Location of Sampling Transects Established in Gable

Mountain Pond During Preliminary Survey .................... A.2

A.2 Map of Sediment Types Constructed During

Preliminary Survey, June 1984 ........................... A.3

A.3 Water Depths at Each Sampling Location in

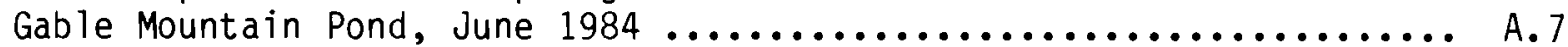

A. 4 Water Depth Contours in Gable Mountain Pond,

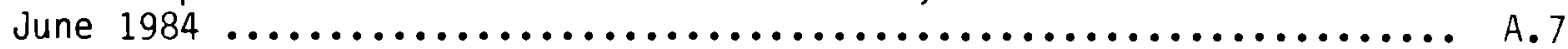

B.1 Diagram and Dimensions of Core Sampler Used at Gable Mountain Pond During 1984 Survey of Pond Sediments

for PCBs

B. 1

C.1 Analytical Scheme for Determination of PCBS in Sediments

C.2 


\section{TABLES}

1 Approximate PCB Isomer Composition of the

Commercially Available Aroclors

2 Concentration of PCBs and Percentage of Water in Top

$5 \mathrm{~cm}$ of Cores from Gable Mountain Pond

A.1 Locations of the Grid Samples Relative to the South

Shoreline Stakes, and the Water Depths at Those

Locations at the Time the Samples Were Taken ...

A. 5 


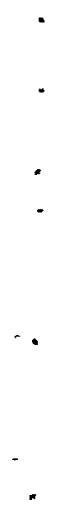


Polychlorinated biphenyls (PCBs) are constituents of insulating fluids used in electrical transformers and capacitors, and are regulated compounds under the Toxic Substances Control Act (TSCA) of 1976 (U.S. EPA 1982). They have been deposited in the soil of the Hanford Site (Figure 1), which is located in southeastern Washington, as a result of road oiling activities, accidental spillages and, perhaps, other disposal practices.

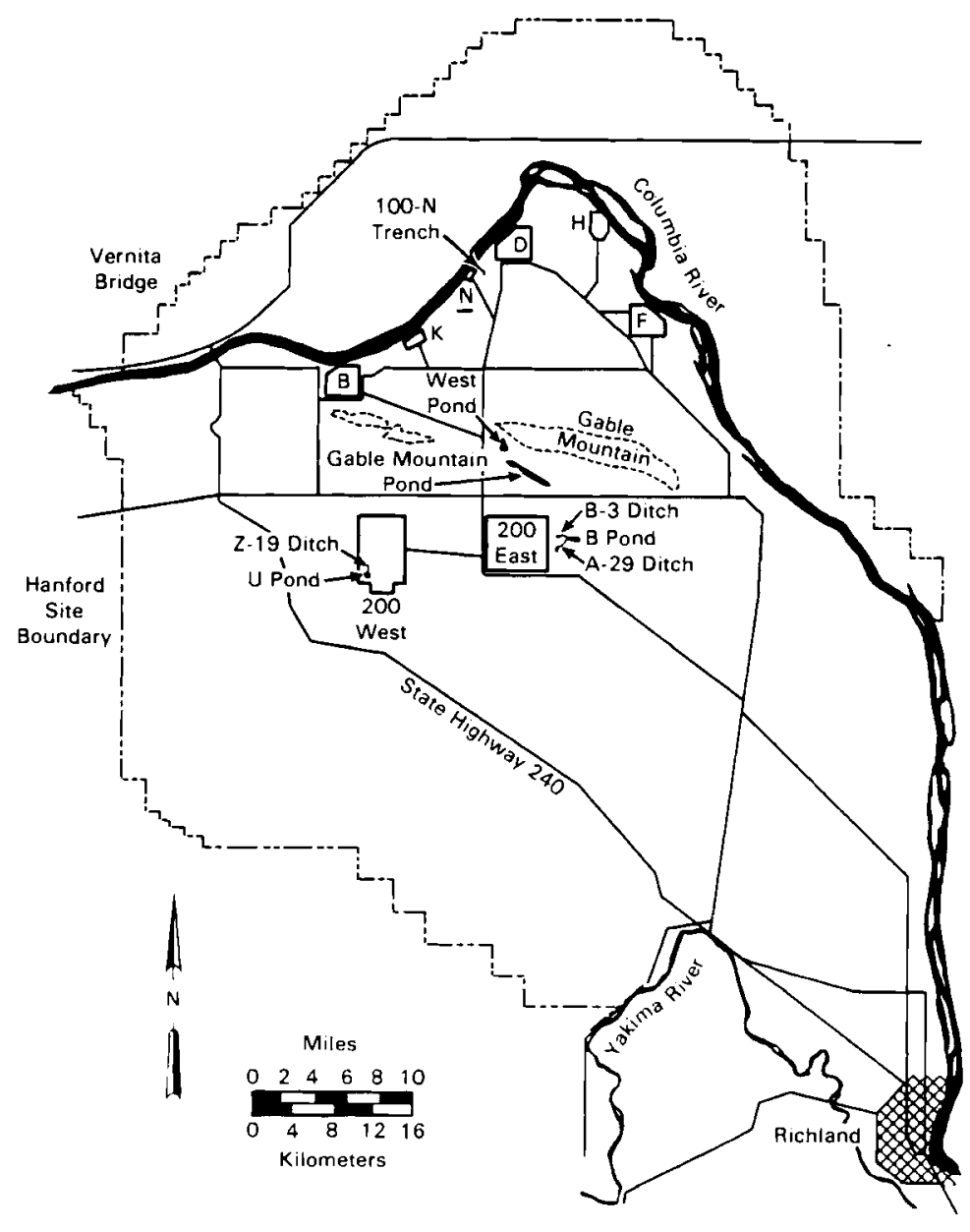

FIGURE 1. Map of the Hanford Site 
Polychlorinated biphenyls (Figure 2), a class of chlorinated aromatic hydrocarbons, are thermally and chemically very stable. The PCBs represent a mixture of specific biphenyl hydrocarbons with varying degrees of chlorination. Substitution of chlorine on the ring structure of biphenyl gives rise to 209 possible chlorobiphenyl isomers. In commercial preparations, mixtures of chlorobiphenyls are usually present, rather than a single pure compound. The Monsanto Company has been the largest producer of PCBs in the United States and the United Kingdom, and has assigned to them the trade name "Aroclor" followed by a four-digit number. The first two digits of this number indicate the type of mixture, and the last two digits represent the approximate weight percentage of chlorine in the product. The approximate composition of commercially available aroclors is listed in Table 1 . Detailed physical and chemical

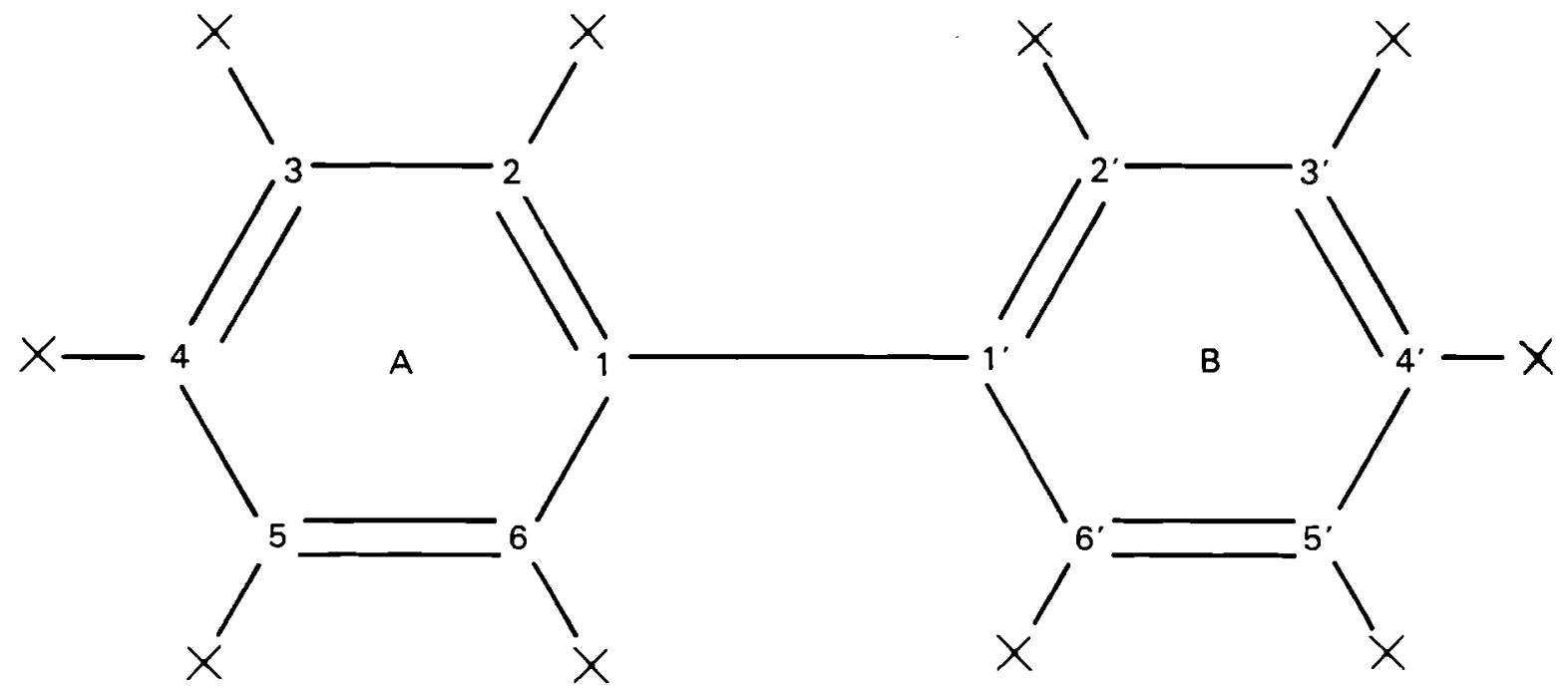

1 - 6 Carbon Atoms in Aromatic Ring A

1' - 6' Carbon Atoms in Aromatic Ring B

$X \quad \mathrm{H}$ or $\mathrm{Cl}$, Depending on Chlorination

FIGURE 2. Biphenyl Structure and Numbering of Carbon Atoms in Each Ring (Pal, Weber and Overcash 1980) 
TABLE 1. Approximate PCB Isomer Composition (\%) of the Commercially Available Aroclors (Pal, Weber and Overcash 1980)

\begin{tabular}{|c|c|c|c|c|c|c|c|c|c|c|c|}
\hline $\begin{array}{c}\text { Empirical } \\
\text { Formula } \\
\end{array}$ & $\begin{array}{c}\text { Number of } \\
\text { Chlorine Atoms }\end{array}$ & $\begin{array}{l}\text { Number of } \\
\text { Isomers }\end{array}$ & $\begin{array}{l}\text { Molecular } \\
\text { Weight }\end{array}$ & $\begin{array}{l}\text { Weight \% } \\
\text { Chlorine }\end{array}$ & 1221 & 1232 & 1252 & $\frac{\text { roc lor }}{1248}$ & 1254 & 1260 & 1016 \\
\hline $\mathrm{C}_{12} \mathrm{H}_{10}$ & 0 & 1 & 154 & 0 & 11 & $<0.1$ & $<0.1$ & -- & $<0.1$ & -- & $<0.1$ \\
\hline $\mathrm{C}_{12} \mathrm{H}_{9} \mathrm{Cl}$ & 1 & 3 & 189 & 18.8 & 51 & 31 & 1 & -- & $<0.1$ & -- & 1.0 \\
\hline $\mathrm{C}_{12} \mathrm{H}_{8} \mathrm{Cl}_{2}$ & 2 & 12 & 223 & 31.8 & 32 & 24 & 16 & 2 & 0.5 & -- & 20 \\
\hline $\mathrm{C}_{12} \mathrm{H}_{7} \mathrm{Cl}_{3}$ & 3 & 24 & 258 & 41.3 & 4 & 28 & 49 & 18 & 1.0 & -- & 57 \\
\hline $\mathrm{C}_{12} \mathrm{H}_{6} \mathrm{Cl}_{4}$ & 4 & 42 & 292 & 48.6 & 2 & 12 & 25 & 40 & 21 & -- & 21 \\
\hline $\mathrm{C}_{12} \mathrm{H}_{5} \mathrm{Cl}_{5}$ & 5 & 46 & 326 & 54.3 & $<0.5$ & 4 & 8 & 36 & 48 & 12 & $<0.1$ \\
\hline $\mathrm{C}_{12} \mathrm{G}_{4} \mathrm{Cl} \mathrm{l}_{6}$ & 6 & 42 & 361 & 58.9 & -- & $<0.1$ & -- & 4 & 23 & 38 & -- \\
\hline $\mathrm{C}_{12} \mathrm{H}_{3} \mathrm{Cl}_{7}$ & 7 & 24 & 395 & 62.8 & -- & -- & $<0.1$ & -- & 6 & 41 & -- \\
\hline $\mathrm{C}_{12} \mathrm{H}_{2} \mathrm{Cl}_{8}$ & 8 & 12 & 430 & 66 & -- & -- & -- & -- & -- & 8 & -- \\
\hline $\mathrm{C}_{12}{ }^{\mathrm{H}_{1} \mathrm{Cl}_{9}}$ & 9 & 3 & 464 & 68.7 & $=$ & $=$ & 二- & 三 & -- & 1 & $=$ \\
\hline Average $M$ & lecular Weight & & & & 201 & 232 & 267 & 300 & 328 & 376 & 258 \\
\hline
\end{tabular}


properties of individual PCBs and their commercially available technical mixtures have been compiled by Hutzinger, Safe and Vitko (1974).

Polychlorinated biphenyls are synthetics and do not occur naturally. Introduction of PCBs into the environment increased with their mass-scale manufacture and use (e.g., as insulating fluids and fire retardants) since 1930. It is speculated that PCBs are distributed worldwide and, similar to chlorinated pesticides, tend to accumulate in food chains from contaminated environments and have exhibited effects on human health (Kuratsune et al. 1972). The PCBs released into the North American environment amount to roughly $3.5 \times 10^{5}$ tons, of which $3.0 \times 10^{5}$ tons are buried and stored in landfills or dumps. The remainder is associated with sediments of lakes and rivers and is widely distributed over land and water through aerial fallout and spills (Nisbet and Sarofim 1972).

The study described in this report was performed for the U.S. Department of Energy (DOE) by Pacific Northwest Laboratory (PNL). The objective was to estimate the distribution and concentration of polychlorinated byphenyls (PCBs) in Gable Mountain Pond, which is located on the Hanford Site.

Gable Mountain Pond (Figure 3) was created in 1957 to receive cooling water from the PUREX Plant, where reactor fuels are processed. The water, taken from the Columbia River between 100-B and 100-D reactor sites, is used primarily to cool large chemical processing tanks. There is no permanently defined outlet to the pond, and input is matched by percolation through the pond's bottom and by surface evaporation, thus avoiding any return of the water directly to the Columbia River. On a few occasions, radionuclides have inadvertently entered the cooling stream. The largest of such events occurred when low levels of actinides and mixed fission products entered the pond in 1964, following a rupture in the cooling coils at the PUREX Plant. In comparison to other ponds and ditches on the Hanford Site (U Pond, B Pond, West Pond, 100-N Trench, Z-19 Ditch, B-3 Ditch, and A-29 Ditch, in Figure 1), Gable Mountain Pond would be classified as "medium" (of low, medium, and high) with regard to its radiological properties (radionuclide concentrations in sediment and water). It is the largest of the Hanford ponds and has a relatively slow flushing rate (Emery and McShane 1978; Rickard, Fitzner and Cushing 1981). 


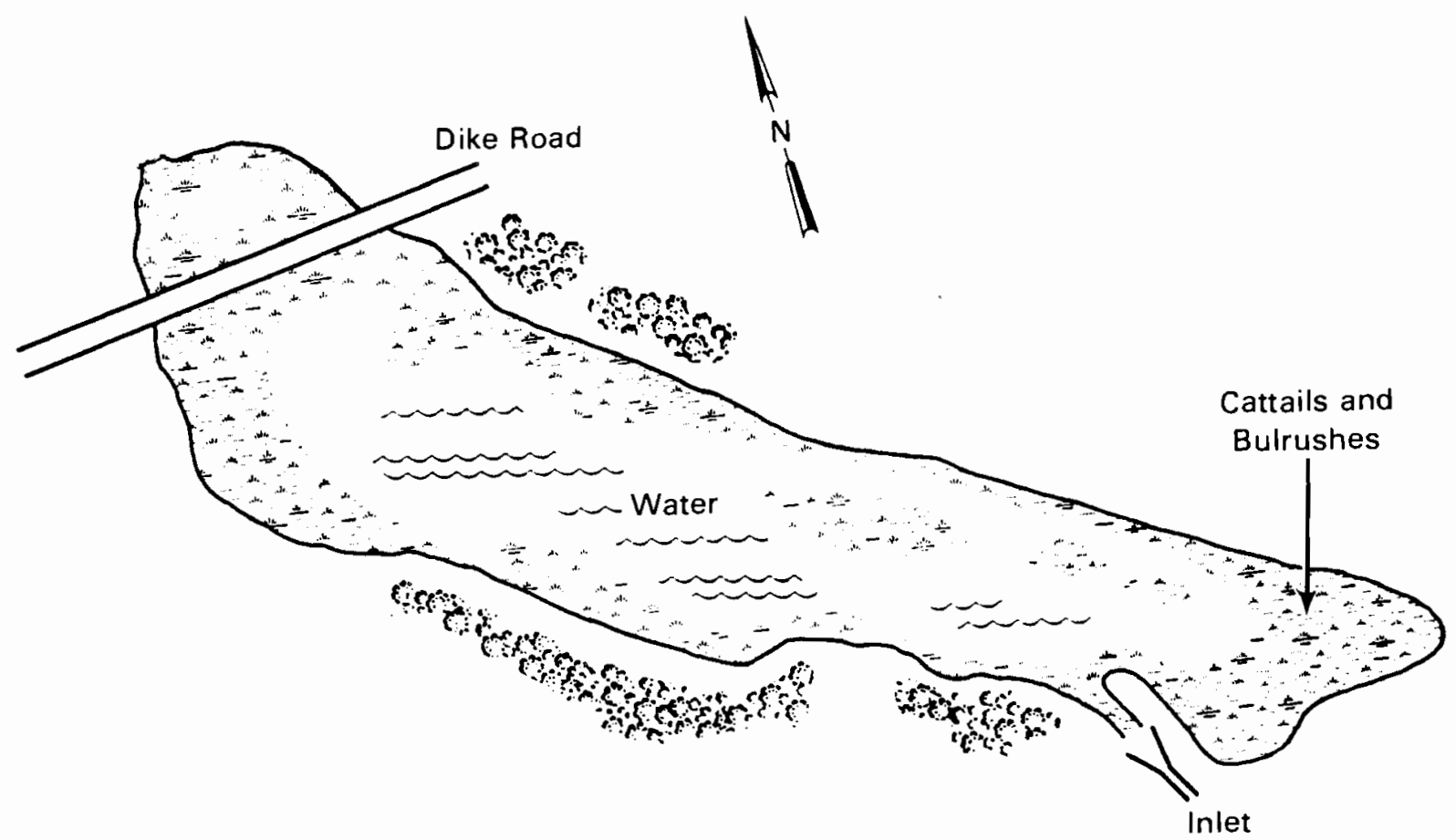

FIGURE 3. Gable Mountain Pond

Pacific Northwest Laboratory recently detected PCBs in sediments from Gable Mountain Pond during a study being performed by DOE on the bioavailability of PCBs to great blue herons nesting on and near the Hanford Site (Riley et a1. 1986). The purpose of our current study (performed for Rockwell Hanford Operations, the operator of Gable Mountain Pond) was to map the distribution and estimate the amount of PCBs in Gable Mountain Pond. This information was needed to ensure proper stabilization and/or waste management of the pond, in accordance with current federal regulations governing the disposal of $\mathrm{PCB}$-containing wastes to the environment. 



\section{STRATEGY FOR SURVEYS}

In order to meet our objective and estimate the distribution of PCBs in Gable Mountain Pond, it was necessary to sample sediments in various areas of the pond. The collection of sediment core samples proceeded in two phases. In Phase I, a short, preliminary survey of the pond was conducted to test equipment and identify any future sampling problems. Phase II involved comprehensive sampling: cores were collected on a uniform grid over the area of the pond. Surface subsamples from a select group of cores were analyzed for PCBs. Using these data and a statistical technique known as kriging (Clark 1982), we developed a contour map of PCB concentrations in the pond surface sediments. Two standard deviation limits were calculated for each of the estimated PCB concentration contours in Gable Mountain Pond.

\section{PHASE I: PRELIMINARY SURVEY}

A brief, initial survey of the pond was conducted in the first phase of the study, to gather information in order to design a comprehensive sampling strategy and to check for field sampling difficulties. The survey had five objectives:

1. to identify the different substrate types in the pond and determine the ease with which we could sample each type

2. to estimate the areas and locations of each substrate type in the pond

3. to determine the length and quality of cores that could be taken from each of the substrate types

4. to test the sampling equipment and selected sampling techniques

5. to refine our map of the pond and get accurate dimensions of the area. to be sampled during the comprehensive sampling phase.

In the preliminary survey, 15 transects were constructed at 300-ft intervals across the width of Gable Mountain Pond (numbers 1 through 15 in Figure 4). These transects were used during Phase II as framework for a $150-\mathrm{ft}$ 


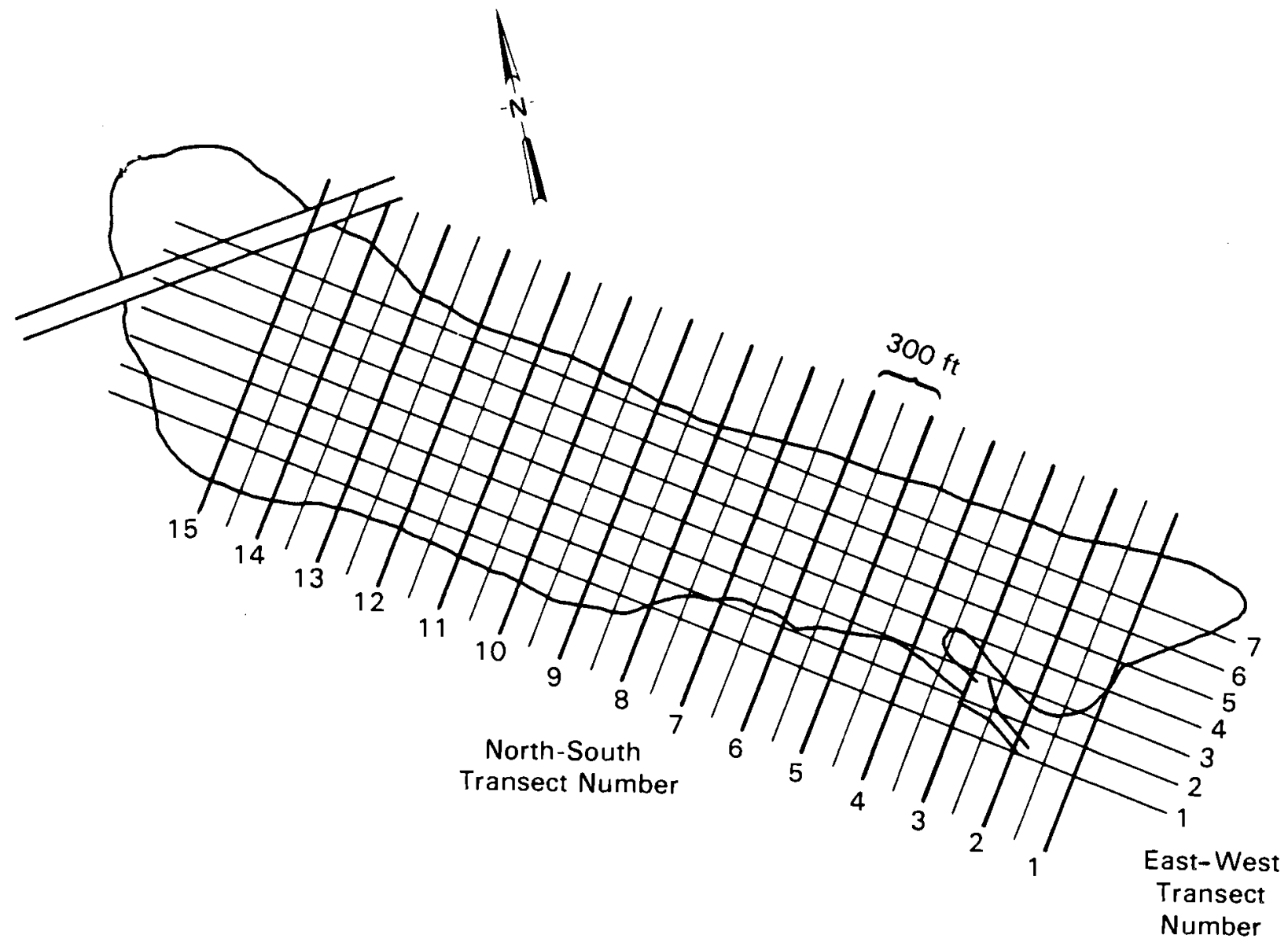

FIGURE 4. Placement of Transects in Gable Mountain Pond (unnumbered transects were made during the comprehensive-sampling phase; samples are identified by the north-south transect number followed by the east-west transect number)

grid required for comprehensive sampling. Details for placement of the transects are provided in Appendix A. Water and sediment depths were measured approximately every $20 \mathrm{ft}$ along each transect. To accomplish these measurements in the short time allowed, a boat was driven in concentric rings around the pond, starting at the shoreline, and ending in the middle. Each ring was about $20 \mathrm{ft}$ farther from the shore than the previous one. As each transect was crossed, the water depth was measured from the boat, on the transect, with a yardstick. The stick was then driven into the sediment, and a measurement was taken again, to estimate sediment depths. Water and sediment depth 
measurements taken along these transects were used to construct a rough sediment map of the pond. Water depths were also recorded at each sampling location during the comprehensive sampling. Maps of the water depths and sediment types are included in Appendix $A$.

Once the different substrates were identified from the transect data, we sampled each of the sediment types. In addition, approximate dimensions of the pond were determined from the lengths and number of transects.

PHASE II: COMPREHENSIVE COLLECTION AND CHEMICAL ANALYSIS OF SEDIMENT SAMPLES

In the second phase of our study, sediment cores from open-water areas were collected on a 150-ft grid. The grid (north-south and east-west transects) is depicted in Figure 4, while samples actually collected are shown in Figure 5. Grid samples were identified by the north-south transect number followed by the east-west transect number. Details as to the method by which these points were located are presented in Appendix A.

Between June 12 and June 21, 1984, 130 core samples (each 4 in. long) were collected in the open water at Gable Mountain Pond. Eighty of these samples were collected at the grid points, as indicated in Figure 5. Water depths were measured at each location as the samples were taken. Forty-five "replicate" cores were collected, five at each of nine randomly selected locations throughout the pond. Five cores were also collected from five locations, selected by judgment sampling, at the west end of the pond across the dike. In addition, three 1-ft cores were collected from the deepest portions of the pond. Subsamples from approximately half of the cores collected at the grid points were analyzed for PCB content; these were randomly chosen from the 80 main sampling grid samples.

Twenty-nine grab samples were systematically collected from cattail areas. Cattail samples had not been collected during the preliminary survey. Sample locations were selected at approximately equidistant intervals along the perimeter in about $1 \mathrm{ft}$ of water (Figure 5). Five replicate grab samples were also taken at three randomly selected locations in the cattail areas. These 


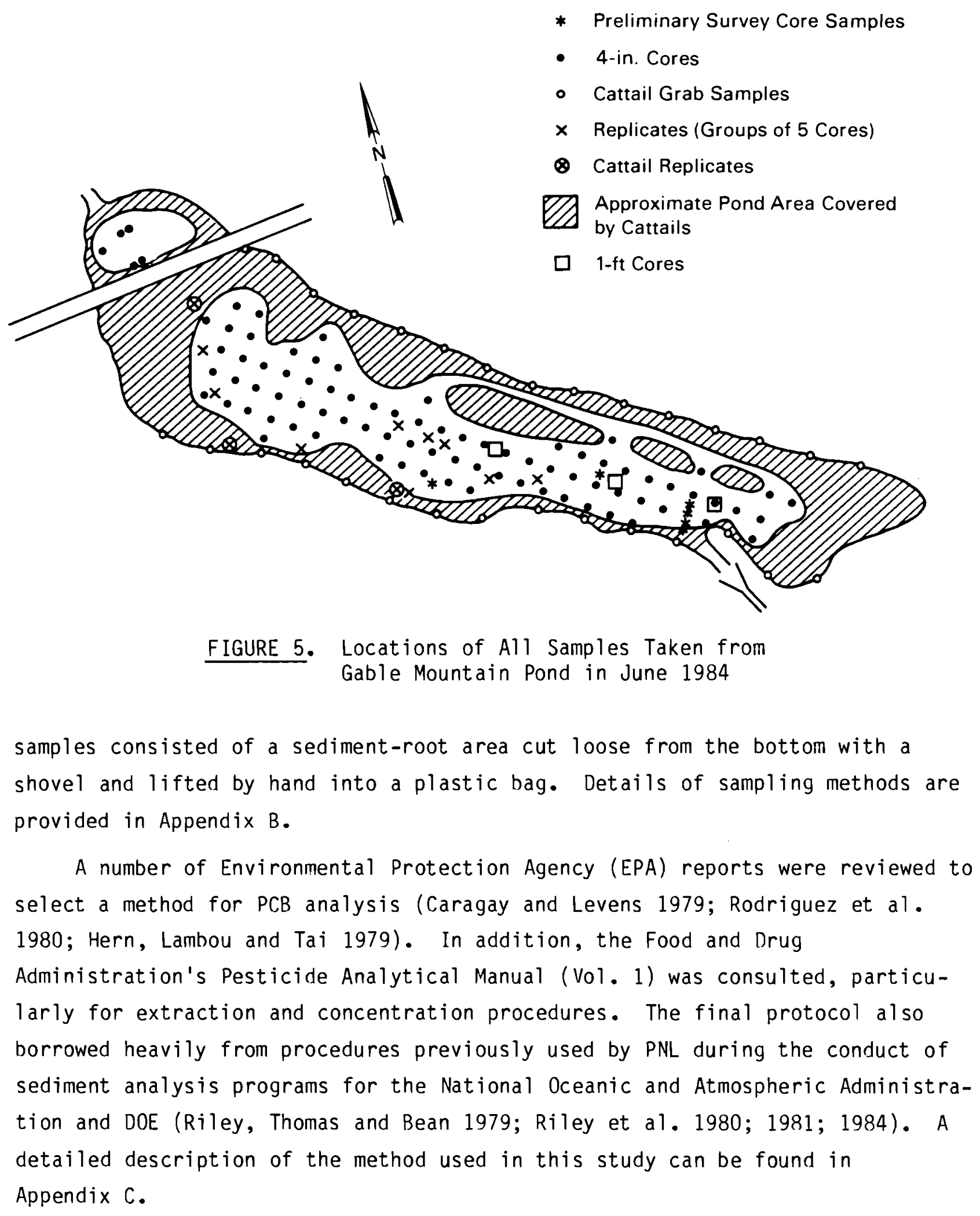


Briefly, the analysis method consists of exhaustive Soxhlet extraction of a wet sediment subsample with an azeotropic mixture of benzene methanol, concentrating the extract into hexane, removing interfering sulfur by shaking the extract with metallic mercury, followed by capillary electron capture gas chromatographic (GC) analysis. Both environmental and analytical samples (Aroclor 1260) were used to identify and quantify the PCBs present. We found that because of interference by several unknown electron-capturing components, the best quantitative results were obtained when selected PCB peaks were integrated (Figure 6; see Appendix $C$ for more detail).

Some samples that were collected were not analyzed as a part of this study. They have been archived in freezers for possible future chemical analysis.

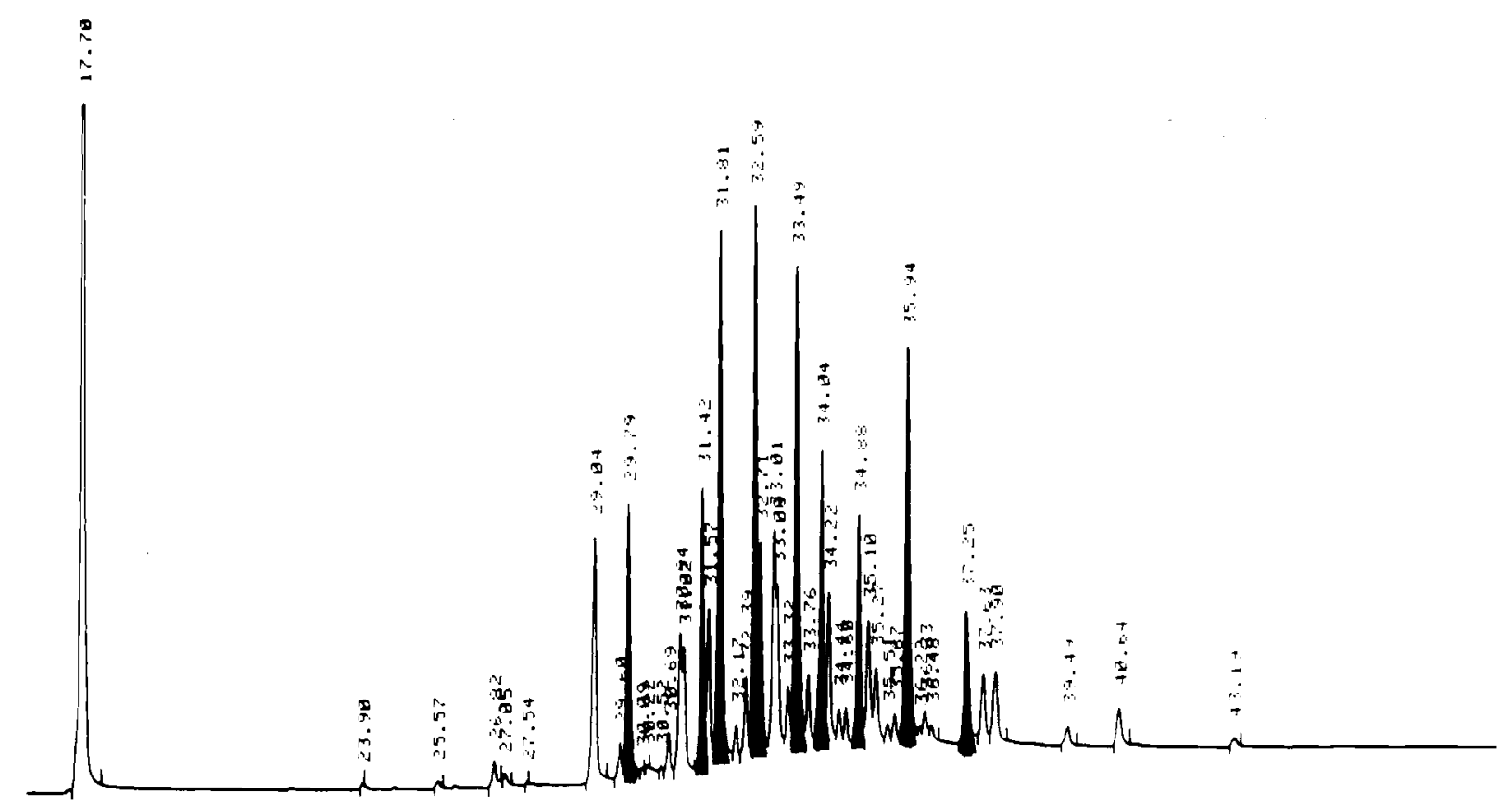

FIGURE 6. Gas Chromatograph Peaks in Aroclor 1260 (darkened areas), Used in the Quantification of Total PCBs Contained in Environmental Samples 


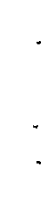


RESULTS

Examination of data from the preliminary survey indicated that the physical characteristics of the pond and the potential for successful collection of cores varied with composition of the pond bottom. The bottom was covered by a sandy layer that varied in thickness over the pond. In general, the thickness of this layer was 6 in. or less; it was totally absent on the north side of the pond around the cattail islands. Water depths varied from $1.0 \mathrm{ft}$ to $8.2 \mathrm{ft}$ for each sampling location and are listed in Table A-1 of Appendix A. We concluded that 6-in. sediment cores could be taken at almost all areas in the open-water section of the pond. The coring device is described in Appendix $B$.

The entire perimeter of the pond was overgrown with cattails and other aquatic macrophytes. These "cattail" areas contained sediment mixed with roots and decaying vegetation. The pond bottom beneath the cattails varied from very little sediment (bentonite-clay composition) to areas with over $0.5 \mathrm{~m}$ of sediment. We concluded that representative cores could not be collected from these areas, so we took, instead, a separate set of grab samples (cattail grab samples, figure 5). The recently flooded areas around the pond were not sampled in this study.

From the top $5 \mathrm{~cm}$ of the sample cores, 40 samples of sediment $(100 \mathrm{~g}$, wet weight) were removed and were analyzed for PCBs by the method outlined in Appendix $C$. The results of this analysis are presented in Table 2; the table also includes the sample location code and the percentage of water associated with the sediment sample. The data are reported on the basis of micrograms per kilogram dry sediment $(\mu \mathrm{g} / \mathrm{kg})$, which corresponds to parts per billion (ppb).

All samples, with one exception, were found to contain the specific PCB mixture Aroclor 1260. No other PCB mixture was found. In only one of the 40 samples could PCBs not be detected (1ocation 2.5-5, see Figure 4). Recovery studies showed that the analytical procedure resulted in essentially complete extraction of PCBs from samples spiked at a 31-ppb level, with a standard deviation of about $20 \%$ ( $6 \mathrm{ppb})$.

Some of the samples contained non-PCB components. It is likely that these components are chlorinated pesticide residues, as pesticides are ubiquitous in 
TABLE 2. Concentration of PCBs and Percentage of Water in Top $5 \mathrm{~cm}$ of Cores from Gable Mountain Pond

\begin{tabular}{|c|c|c|}
\hline Core Sample No.(a) & $\begin{aligned} & \% \text { Water } \\
& 100 \text { g-dry wt } \\
&\end{aligned}$ & $\begin{array}{l}\text { Concentration of Aroclor } \\
1260(\mu \mathrm{g} / \mathrm{kg}, \mathrm{ppb}) \\
\end{array}$ \\
\hline T6-3 & 79.2 & 69 \\
\hline$T 7-4$ & 75.1 & 36 \\
\hline T65-5 & 73.5 & 69 \\
\hline T10-5 & 62.2 & 18 \\
\hline T8.5-3 & 75.8 & 41 \\
\hline T14.5-4 & 40.3 & 4 \\
\hline T15-5 & 80.8 & 28 \\
\hline T12-4 & 26.2 & 3 \\
\hline$T 10-3$ & 31.1 & 5 \\
\hline T9.5-2 & 54.3 & 13 \\
\hline$T 4.5-5$ & 74.1 & 51 \\
\hline T11-4 & 44.0 & 6 \\
\hline T2. 5-5 & 32.4 & N.D. (b) \\
\hline$T 5-5$ & 79.4 & 11 \\
\hline T5-3 & 40.8 & 27 \\
\hline T13-2 & 84.5 & 66 \\
\hline T6-6 & 40.9 & 8 \\
\hline T2. 5-6 & 74.1 & 11 \\
\hline$T 8-3$ & 72.0 & 50 \\
\hline T5.5-5 & 74.7 & 40 \\
\hline T14-2 & 44.8 & 5 \\
\hline T5.5-4 & 76.4 & 82 \\
\hline T9.5-3 & 80.5 & 52 \\
\hline$T 4.5-4$ & 77.7 & 148 \\
\hline T6-4 & 77.8 & 38 \\
\hline T2. 5-4 & 59.7 & 20 \\
\hline T8-4 & 29.4 & 5 \\
\hline T6.5-3 & 47.7 & 11 \\
\hline T13-4 & 24.7 & 2 \\
\hline T4-6 & 22.0 & 5 \\
\hline T11.5-3 & 47.4 & 15 \\
\hline T6.5-4 & 77.6 & 59 \\
\hline T10.5-2 & 83.1 & 44 \\
\hline$T-13-3$ & 29.3 & 4 \\
\hline$T-5.5-3$ & 68.8 & 46 \\
\hline T12.5-4 & 47.4 & 5 \\
\hline T7-5 & 43.2 & 9 \\
\hline T13-5 & 40.7 & 7 \\
\hline T3. 5-4 & 26.1 & 6 \\
\hline T7.5-2 & 23.6 & 3 \\
\hline
\end{tabular}

(a) Samples were identified by the northsouth transect number followed by the east-west transect number.

(b) N.D. indicates that no levels were detected. 
the environment and are detected by the electron-capture detector that we used. We made no attempt to identify these compounds.

Of the 39 samples that contained PCBs, none contained as much as $1 \mathrm{ppm}$. Only nine samples contained $50 \mathrm{ppb}$ or more, and only one was found to exceed $100 \mathrm{ppb}$ (Table ? and Figure 7.).

Figure 8 is a map of the statistically estimated contours of PCB concentrations found in Gable Mountain Pond. The highest concentration contour plotted in this figure is $100 \mathrm{ppb}$, located just beyond the mouth of the inlet. The dotted line around the $100-p p b$ contour is the +2 standard deviation confidence limit on that contour. The +2 standard deviation band is very small and indicates that the estimate of the 100-ppb contour is fairly precise.

Had the PCB concentrations in the sediments approached limits of concern (as specified under TSCA), similar confidence bands would have been plotted for all of the estimated contours. Any particularly wide confidence bands would indicate areas in which additional samples should be analyzed to establish, with acceptable certainty, the relationship between the sediment PCB concentrations and the limits of concern. 


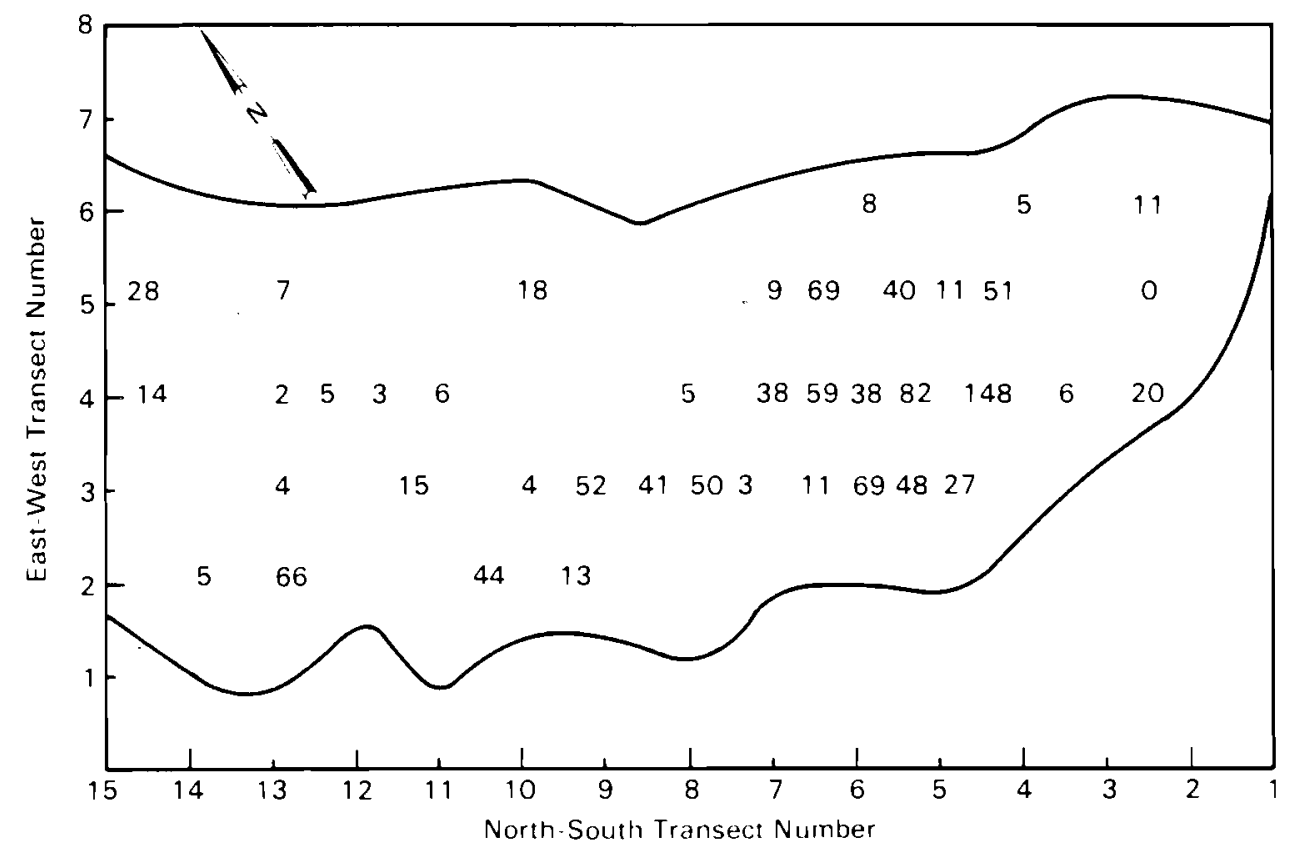

FIGURE 7. Observed PCB Concentrations $(\mu \mathrm{g} / \mathrm{kg})$ in Gable Mountain Pond Sediments (forty sampling stations were randomly selected from a grid of 80 available samples)

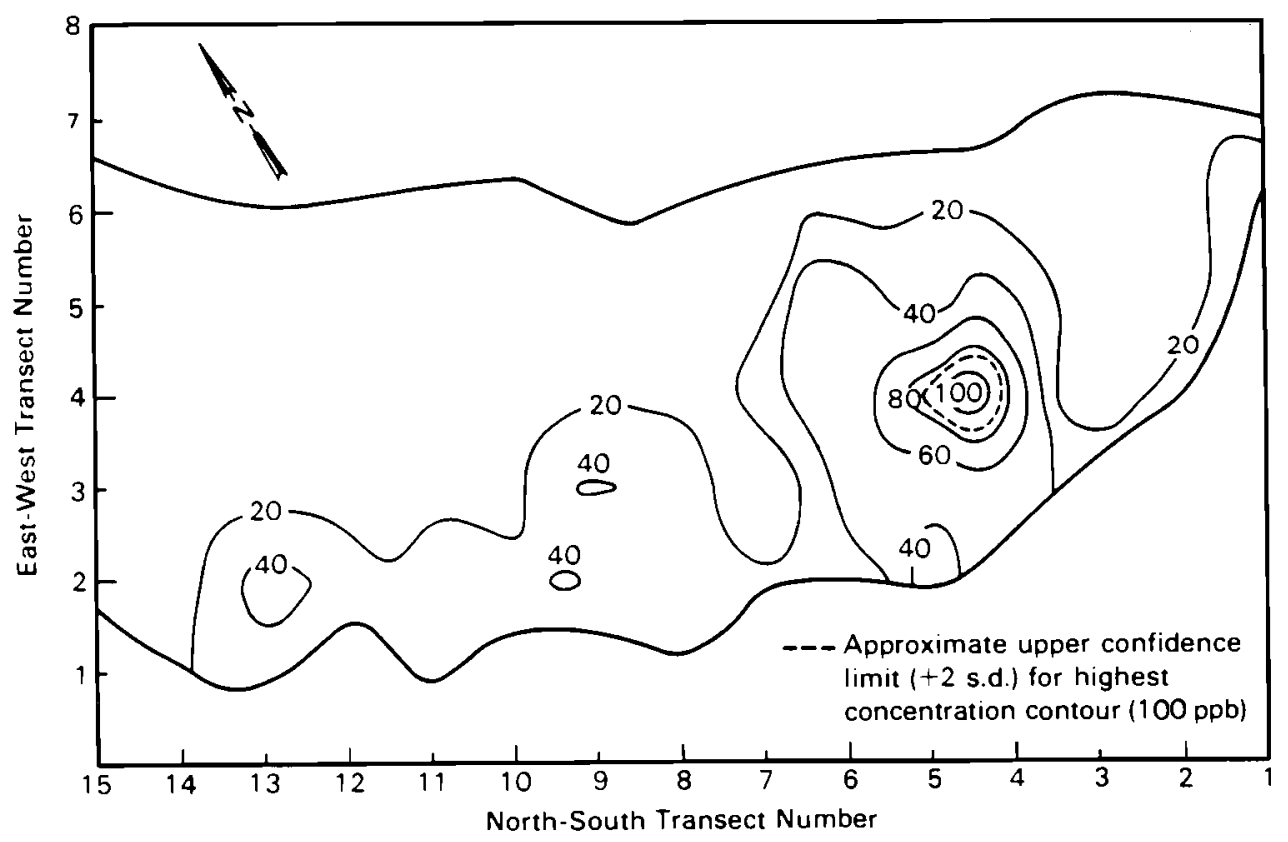

FIGURE 8. Contour Map Indicating Predicted Concentration ( $\mu \mathrm{g} / \mathrm{kg})$ of PCBs in Gable Mountain Pond Sediments 
CONCLUSIONS

The open-water area of Gable Mountain Pond was considerably smaller than that estimated by Emery and McShane (1978). Additionally, there were newly flooded areas, particularly on the south shore. Depths along the south shore were greater than in the 1978 study.

The highest PCB concentrations were found near the inlet pipe. The distribution of PCBs in the pond is consistent with the hypothes is that they entered the pond primarily through the inlet pipe and spread along the length of the pond in a westerly direction. There is one unusually high concentration measurement in the southeastern portion of the pond, on Transect 13. This elevated PCB level might have been caused by a separate input to the pond, or an area in which the PCBs accumulated because of the geology or hydrology of the pond. Statistical comparison of the PCB distribution in relation to the water depths and sediment types does not indicate that PCB concentrations have any relationship to either of these two factors. Therefore, it is more probable that this anomolously high PCB level was caused by a separate discharge to the pond.

Disposal of PCB-containing materials to the environment is controlled under Section 40-CFR-761 of the EPA's Hazardous Waste Regulations, defined in the TSCA Inspection Manual (U.S. EPA 1982). While this regulation defines the quantity and concentration limits for the disposal of chemical wastes to the ground, there is no mention of the regulation of historically disposed wastes in contained or uncontained landfills or waste ponds. Historical waste disposal sites are regulated under the Comprehensive Environmental Response, Compensation, and Liability Act of 1980 (CERCLA or Superfund) or under the Continuing Releases provision of Section 3004(u) of the Resource Conservation and Recovery Act. Under TSCA it is acceptable to dispose of waste liquids containing 50 to $500 \mathrm{ppm}$ to approved chemical waste landfills. For wastes containing more than 500 ppm PCBs, incineration is required. Prior to implementing these disposal practices, a waste landfill has to be approved by the EPA Regional Administrator. 
The EPA is filing civil suits against companies allegedly violating PCB provisions of Section $6(e)$ of TSCA that require them to clean up all spill sites where PCB concentration is greater than $50 \mathrm{ppm}$ (U.S. EPA 1984). Thus, it appears that EPA is using existing regulations to make cleanup decisions concerning PCBs released in spill situations. However, concentrations of PCBS in surface sediment samples from Gable Mountain Pond ranged from 2 to $148 \mathrm{ppb}$, which is roughly two to four orders of magnitude below the regulated upper concentration limit for disposal of PCB-contaminated waste. 


\section{REFERENCES}

Caragay, A. B., and P. L. Levens. 1979. Evaluation of Protocols for Pesticides and PCBs in Raw Wastewater. EPA-600/2-79-1, 66, U.S. Environmental Protection Agency, Washington, D.C.

Clark, I. 1982. Practical Geostatistics. Applied Science Publishers Ltd., London.

Clark, R. C., and J. S. Finley. 1973. "Techniques for Analysis of Paraffin Hydrocarbons and for Interpretation of Data to Assess 0il Spill Effects in Aquatic Organisms." In Proceedings of Joint Conference on Prevention and Control of 0 il Spills, American Petroleum Institute, Washington, D.C.

Emery, R. M., and M. C. McShane. 1978. Comparative Ecology of Nuclear Waste Ponds and Streams on the Hanford Site. PNL-2499, Pacific Northwest Laboratory, Richland, Washington.

Hern, S. C., V. L. Lambou and H. Tai. 1979. Pesticides and Polychlorinated Biphenyls in the Achafalaya Basin, Louisiana. EPS-600/4-79-0, 61, U.S. Environmental Protection Agency, Washington, D.C.

Hutzinger, 0., S. Safe and V. Vitko. 1974. The Chemistry of PCBs, pp. 1-39, 113-148, 221-253. CRC Press, Cleveland, 0hio.

Kuratsune, M., T. Yoshimura, J. Matsuzaka and A. Yamaguchi. 1972. "Epidemiologic Study on Yusho, a Poisoning Caused by Ingestion of Rice 0il Contaminated with a Commercial Brand of Polychlorinated Biphenyls." Environmental Health Perspectives $1: 119-228$.

Nisbet, I. C. T., and A. F. Sarofim. 1972. "Rates and Routes of Transport of PCBs in the Environment." Environ. Health Perspect, 1:21-38.

Pal, D., J. B. Weber and M. R. Overcash. 1980. "Fate of Polychlorinated Biphenyls (PCBs) in Soil-Plant Systems." In Residue Reviews: Residues of Pesticides and Other Contaminants in the Total Environment, Vol. 74, ed. F. A. Gunther and J. D. Gunther. Springer-Verlag, New York.

Rickard, W. H., R. E. Fitzner and C. E. Cushing. 1981. "Biological Colonization of an Industrial Pond: Status After Two Decades." Environmental Conservation 8:241-248.

Riley, R. G., B. L. Thomas and R. M. Bean. 1979. Trace Analys is of Organic Pollutants in Duamish River Intertidal Sediment. PNL-SA-7690, Pacific Northwest Laboratory, Richland, Washington. 
Riley, R. G., E. A. Crecelius, D. C. Mann, K. H. Abel, B. L. Thomas and R. M. Bean. 1980. "Quantitation [sic] of Pollutants in Suspended Matter and Water from Puget Sound." NOAA Tech Memo ERL MESA-49, National Oceanic and Atmospheric Administration, Office of Marine Pollution Assessment, Boulder, Colorado.

Riley, R. G., E. A. Crecelius, M. A. O'Malley, K. H. Abel and D. H. Mann. 1981. "Organic Pollutants in Waterways Adjacent to Commencement Bay Puget Sound." NOAA Tech Memo OMPA-12, National Oceanic and Atmospheric Administration, Office of Marine Pollution Assessment, Boulder, Colorado.

Riley, R. G., E. A. Crecelius, R. A. Fitzner, B. L. Thomas, J. M. Gurtisen and N. S. Bloom. 1983. "Organic and Inorganic Toxicants in Sediment and Birds from Puget Sound." NOAA Tech Memo NOS-OMS-1, National Oceanic and Atmospheric Administration, Rockville, Maryland.

Riley, R. G., E. A. Crecelius, R. A. Fitzner, B. L. Thomas, J. M. Gurtisen and N. S. Bloom. 1984. "Organic and Inorganic Toxicants in Sediment and Birds from Puget Sound." NOAA Technical Memorandum NOSOMS-1, National Oceanic and Atmospheric Administration, Rockville, Maryland.

Riley, R. G., R. M. Bean, R. E. Fitzner, D. W. Neitzel and W. H. Rickard. 1986. A Preliminary Survey of Polychlorinated Biphenyls (PCBs) in Aquatic Habitats and Great Blue Herons on the Hanford Site. PNL-5685, Pacific Northwest Laboratory, Richland, Washington.

Rodriguez, C. F., W. A. McMahon and R. E. Thomas. 1980. Method Development for Determination of Polychlorinated Hydrocarbons in Municipal STudge. EPA600/2-80-0, 29, U.S. Environmental Protection Agency, Washington, D.C.

U.S. Environmental Protection Agency (EPA). 1982. Toxic Substances Control Act Inspection Manual. Volume 1. Government Institutes, Inc., Rockville, Maryland.

U.S. Environmental Protection Agency (EPA). 1984. "PCB Disposal-Update." In Toxics-Pesticides, p. 13. EPA Environmental Policy Alert, August 1, 1984, Washington, D.C. 
APPENDIX A

SURVEY METHODS 
. 
APPENDIX A

SURVEY METHODS

TRANSECTS FOR PRELIMINARY SURVEY

For the preliminary survey, 15 transects, spaced $300 \mathrm{ft}$ apart, were established across the width of Gable Mountain Pond. These transects are diagrammed in Figure A.1. All distances were measured using a Leitz transit.

The starting point for surveying the transects is located immediately adjacent to Test Well 699-53-47 (McGahan and Damschen 1979). From this point, a longitudinal transect was established parallel to the longitudinal axis of the pond, on the north side. This longitudinal transect is distant from the pond shoreline because of the difficulty of siting around the weeds and trees growing along the pond shoreline. The northern endpoints of Transects 5-15 were measured along this longitudinal transect in 300- $\mathrm{ft}$ intervals. The transit was rotated $180^{\circ}$ to measure the northern endpoints of Transects 1,2 , and 3 (Figure A.1). The transit was then moved to each of the transect endpoints, and the distances from the endpoints to stakes placed along the shoreline were measured to estimate the actual area covered by water (Figure A.1).

A second longitudinal transect was established on the southern side of the pond, parallel to the northern transect, by placing the transit at three of the northern transect endpoints and sighting lines across the pond at $90^{\circ}$ angles from the northern transect line. This was done at Transects 4,6 , and 14 . The distances across the pond are indicated in Figure A.1. The transit was then placed at the southern endpoint of Transect 6 , and the southern endpoints of Transects 7-15 were measured from that point. The transit was turned $180^{\circ}$ to measure the endpoints of Transect 5. At Transect 4, a second southern longitudinal transect was set closer to the pond to survey the southern endpoints of Transects 1-4. Again, distances to the actual pond shorelines were measured from each of the southern endpoints.

The southern endpoints of two of the transects were located with respect to test wells on the site. Test Well $699-52-48$ is located $221.3 \mathrm{ft}$ from the 


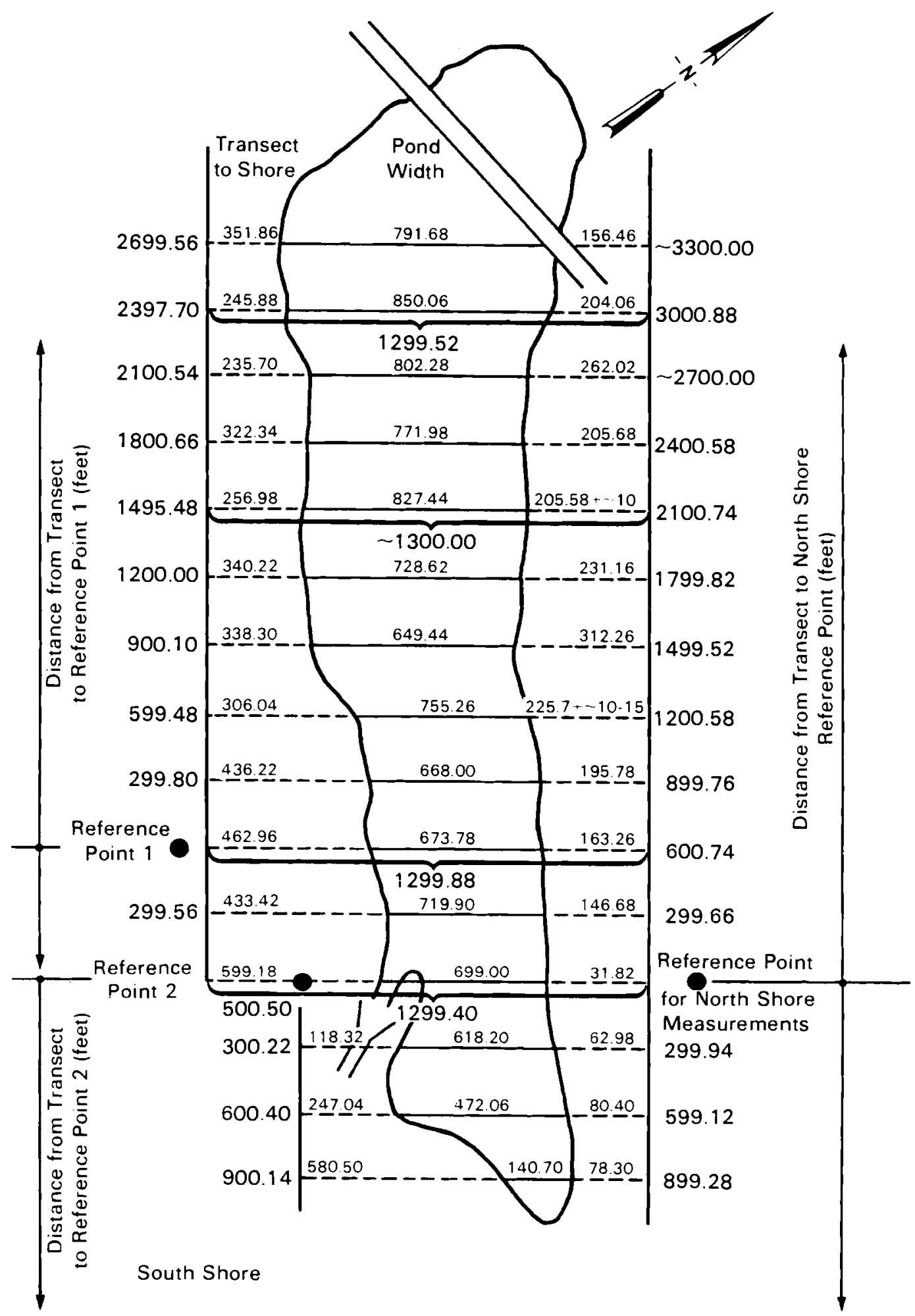

FIGURE A.1. Location of Sampling Transects Established in Gable Mountain Pond During Preliminary Survey (distances in $\mathrm{ft}$ ). 
southern endpoint of Transect 4, at an angle of $29 \mathrm{~min}, 6 \mathrm{sec}$ from

Transect 4. Test Well 699-53-50 is located $186.10 \mathrm{ft}$ away from the southern endpoint of Transect 13, at an angle of $56^{\circ}, 28 \mathrm{~min}, 18 \mathrm{sec}$ from Transect 13.

During the preliminary survey, a rough map was constructed of the sediment types in Gable Mountain Pond (Figure A.2).

Comprehensive Sampling

The samples taken during the comprehensive sampling were located on a 150-ft grid. The transects set up during the preliminary survey, spaced $300 \mathrm{ft}$ apart, were used as a framework for the grid.

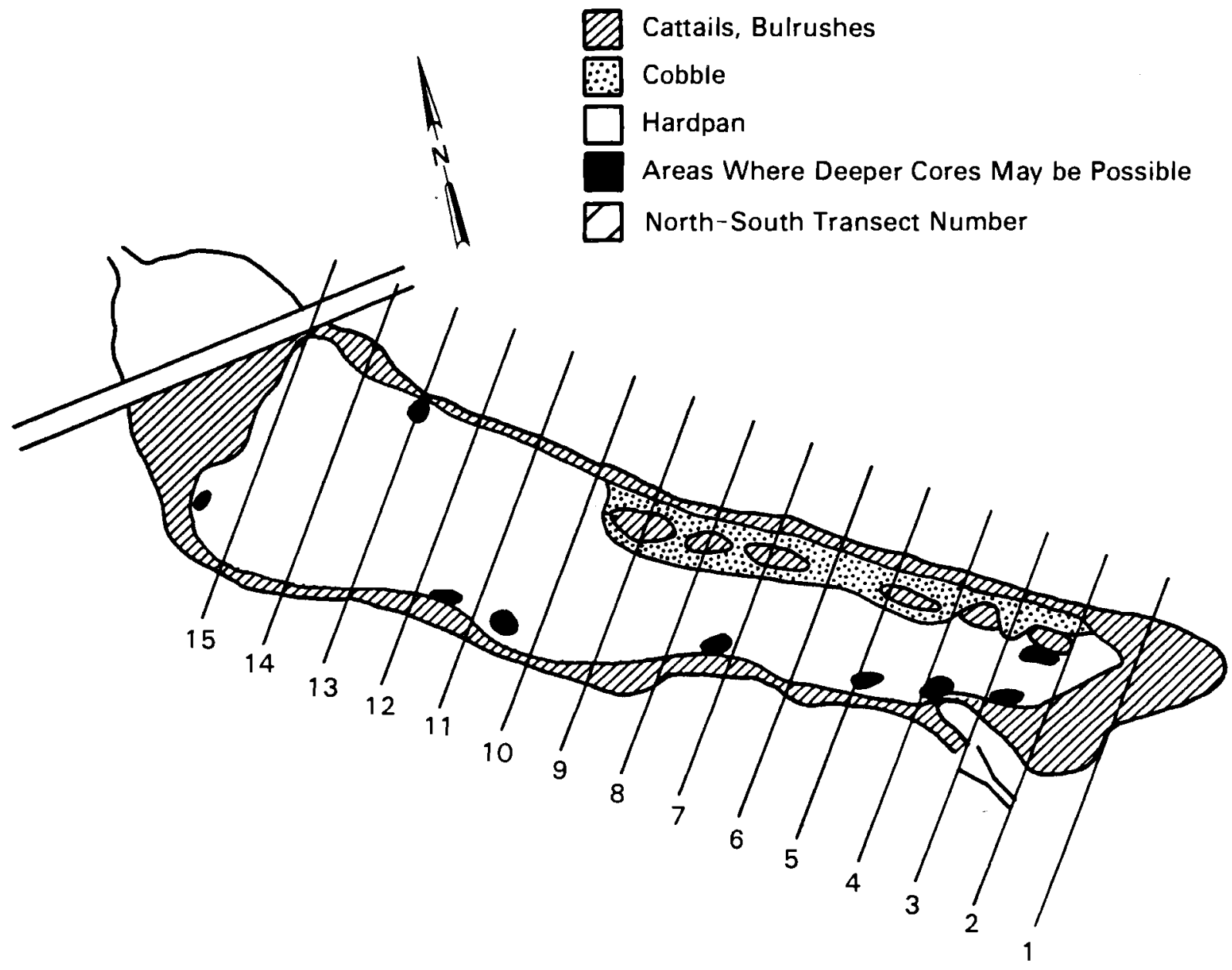

FIGURE A.2. Map of Sediment Types Constructed During Preliminary Survey, June 1984 
As the sampling proceeded, two measured cables were strung across the width of the pond, along two adjacent north-south transects of the original 15. One of the cables was metal; the other was nylon. A third cable (nylon), $300 \mathrm{ft}$ long and marked at $150 \mathrm{ft}$, was strung between the two transect cables, in the east-west direction, $150 \mathrm{ft}$ from the southern shoreline stakes. Three samples were taken with the cables in this configuration, one on each of the 300-ft north-south transects and one halfway between them (150 ft). The eastwest cable was then moved along the north-south transects to a position $150 \mathrm{ft}$ from the last line sampled, and three more samples were taken, two on the north-south transects and one between them. This process was continued over the entire width of the pond. The east-west cables were strung over the next pair of north-south transects, and the process was repeated over the length of the pond. In this way, samples were taken $150 \mathrm{ft}$ apart in all directions.

Transects 1 and 2 were not sampled because that area of the pond was entirely covered with aquatic vegetation. The error in locating a sample was probably no greater than $20 \mathrm{ft}$ in any direction.

Errors in locating the sample sites could be due to errors in measuring with the surveying equipment, the drifting or stretching of the cables over the pond, or the inability of the sampler to locate the exact sampling point under water. No detailed study was made of the sampling methods, however.

The distances of each sampling location along these transects from the southern shore stakes are indicated in Table A.1. A map of the actual water depths at each sampling location is shown in Figure A.3. A map of the estimated water depth contours (produced by the statistical method of kriging) is shown in Figure A.4. 
TABLE A.1. Locations of the Grid Samples Relative to the South Shoreline Stakes, and the Water Depths at Those Locations at the Time the Samples Were Taken

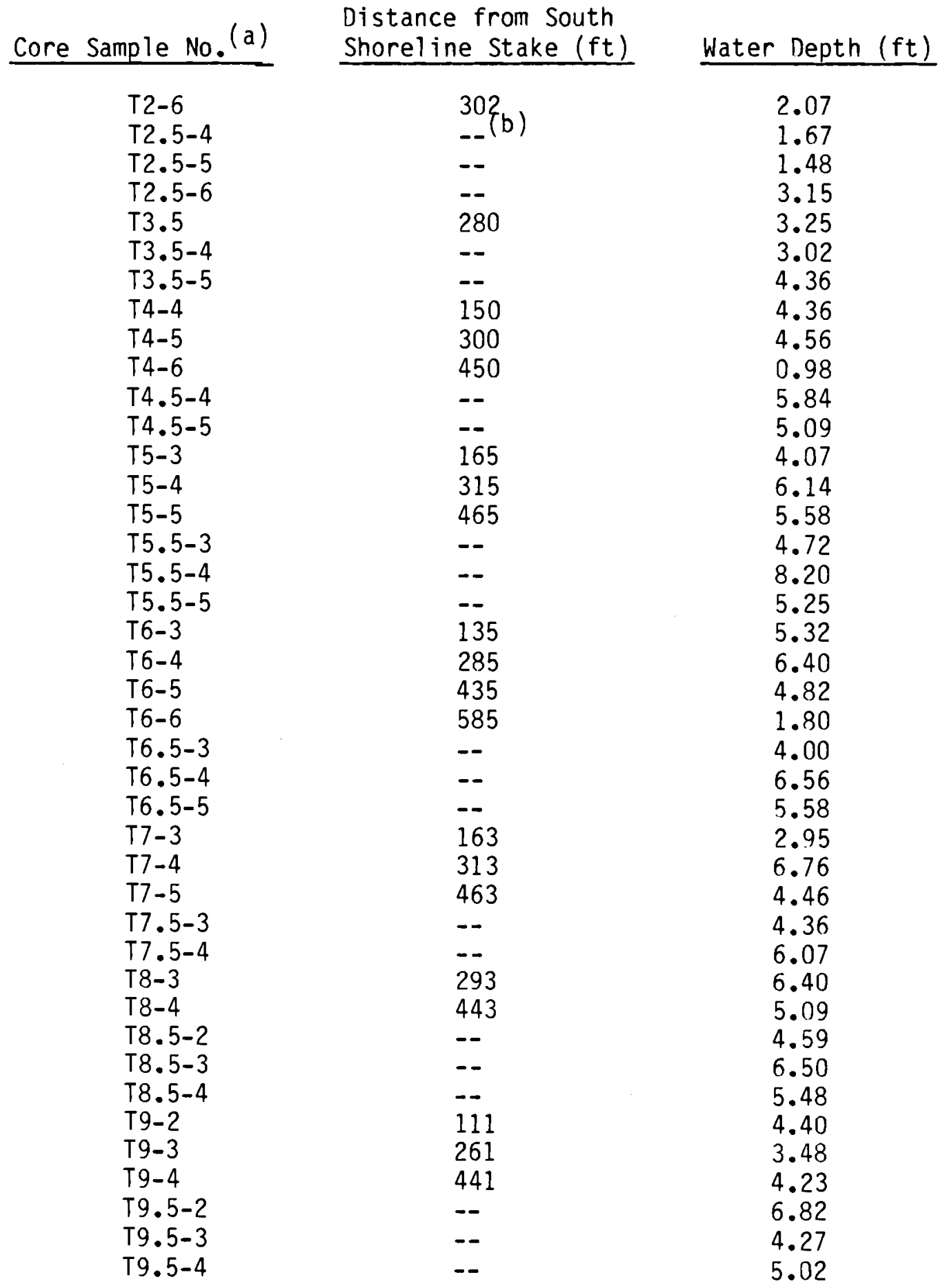


TABLE A.1. (Cont inued)

\begin{tabular}{|c|c|c|}
\hline Core Sample No.(a) & $\begin{array}{l}\text { Distance from South } \\
\text { Shorel ine Stake (ft) } \\
\end{array}$ & Water Depth $(\mathrm{ft})$ \\
\hline$T 10-2$ & 109 & 6.69 \\
\hline$T 10-3$ & 259 & 5.77 \\
\hline T10-5 & 559 & 1.64 \\
\hline$T 10.5-2$ & -- & 6.89 \\
\hline$T 10.5-3$ & -- & 7.61 \\
\hline T10.5-4 & -- & 5.54 \\
\hline T11-3 & 342 & 3.58 \\
\hline T11-4 & 492 & 6.33 \\
\hline T11.5-3 & -- & 6.92 \\
\hline T11.5-4 & -- & 5.94 \\
\hline T12-2 & 127 & 3.58 \\
\hline$T 12-4$ & 427 & 4.95 \\
\hline T12-5 & 577 & 3.84 \\
\hline T12.5-2 & -- & 2.62 \\
\hline$T 12.5-3$ & -- & 3.51 \\
\hline T12.5-4 & - & 5.41 \\
\hline T12.5-5 & -- & 3.45 \\
\hline T12.5-6 & -- & 1.64 \\
\hline T13-1 & 63 & 3.90 \\
\hline T13-2 & 213 & 5.12 \\
\hline$T 13-3$ & 363 & 4.59 \\
\hline T13-4 & 513 & 5.05 \\
\hline T13-5 & 663 & 4.59 \\
\hline$T 13.5-2$ & -- & 3.38 \\
\hline$T 13.5-3$ & -- & 6.46 \\
\hline T13.5-4 & -- & 4.27 \\
\hline T14-2 & 203 & 3.84 \\
\hline T14-3 & 353 & 5.58 \\
\hline T14-4 & 503 & 6.53 \\
\hline$T 14-5$ & 653 & 3.81 \\
\hline T14-6 & 803 & 2.85 \\
\hline T14.5-2 & -- & 3.97 \\
\hline$T 14.5-3$ & -- & 2.95 \\
\hline T14.5-4 & -- & 2.82 \\
\hline$T 14.5-5$ & -- & 6.14 \\
\hline$T 14.5-6$ & -- & 4.43 \\
\hline T15-5 & 547 & -- \\
\hline
\end{tabular}

\footnotetext{
(a) Samples were identified by the north-south transect number followed by the east-west transect number

(b) -- indicates that no sample was taken.
} 


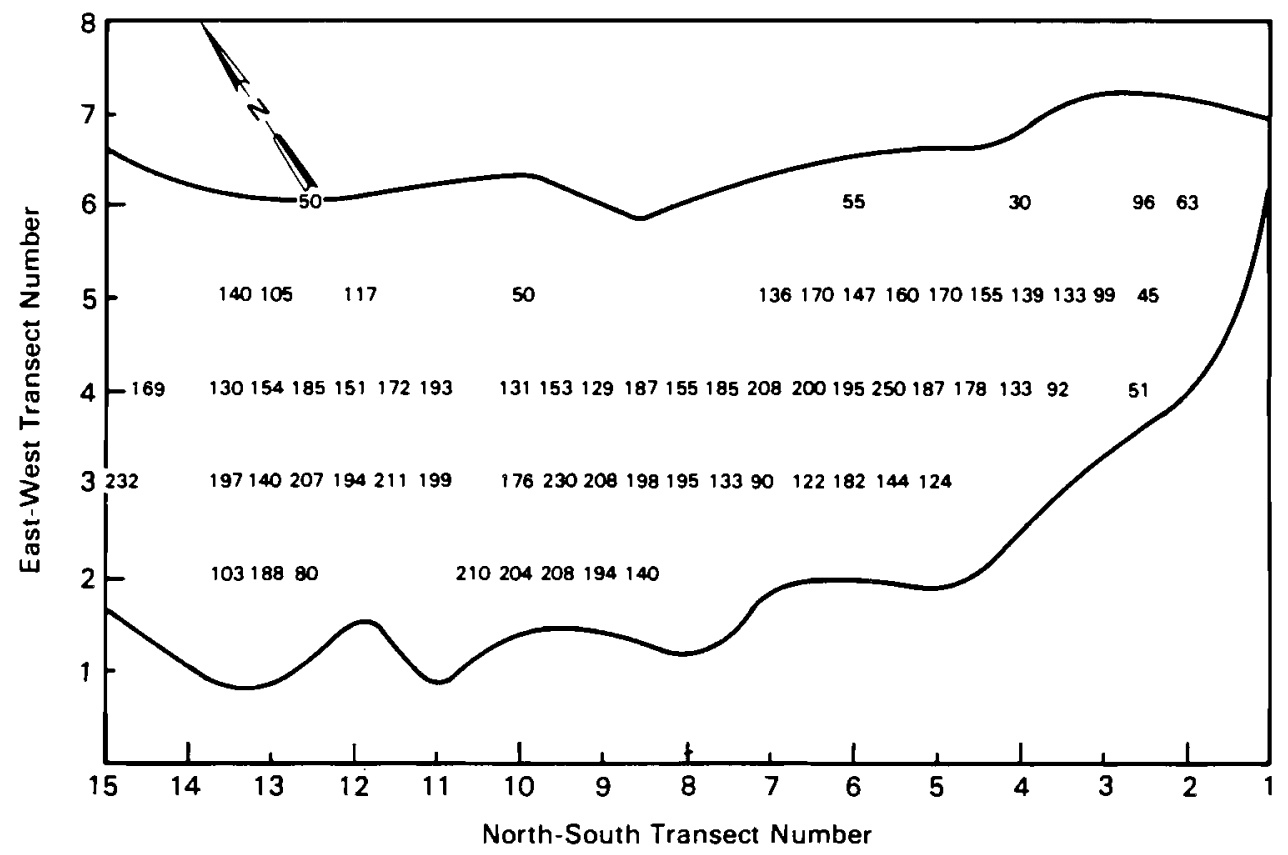

FIGURE A.3. Water Depths ( $\mathrm{cm}$ ) at Each Sampling Location in Gable Mountain Pond, June 1984

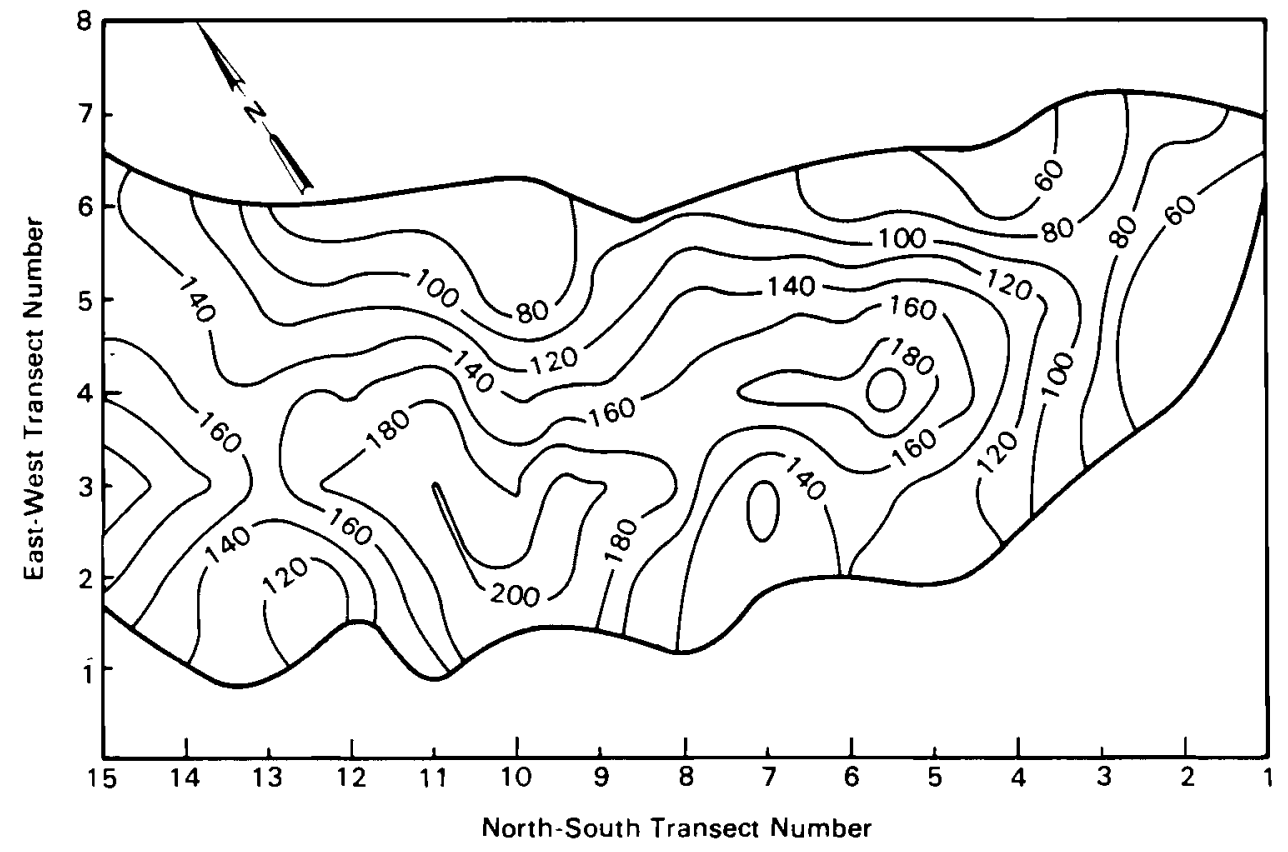

FIGURE A.4. Estimated Water Depth Contours $(\mathrm{cm})$ in Gable Mountain Pond, June 1984 


\section{APPENDIX A REFERENCE}

McGahan, V. L., and W. D. Damschen. 1979. Hanford Wells. PNL-2894, Pacific Northwest Laboratory, Richland, Washington. 


\section{APPENDIX B}

SEDIMENT SAMPLING METHODS 



\section{APPENDIX B}

\section{SEDIMENT SAMPLING METHODS}

Core samples were collected in 4-in. sections of PVC pipe (5-in. diameter). The pipe was beveled at one end to provide a cutting edge for easier insertion into the sediment. Each pipe section was fitted with two PVC pipe caps, one cap at each open end. The sample is illustrated in Figure B.1.

Cores were collected by pushing the pipe section into the sediment, beveled end down. The pipe was pushed by hand to a depth of 4 in., then handexcavated and undermined. One cap was placed on the bottom and the second on the top. In areas where the pond was too deep to wade (i.e., greater than $2 \mathrm{ft}$ ) cores were collected by scuba divers. Pipe section insertion and handexcavation procedures were the same whether by diver or wader.

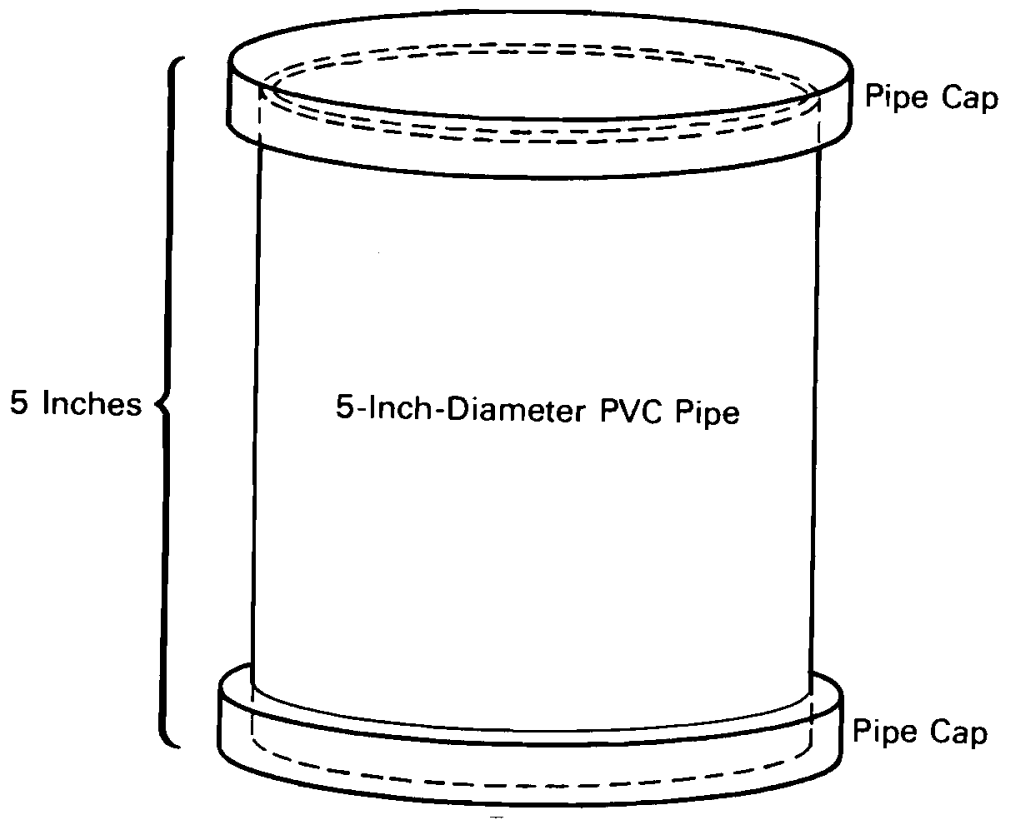

FIGURE B.1. Diagram and Dimensions of Core Sampler Used at Gable Mountain Pond During 1984 Survey of Pond Sediments for PCBs 
Cores were transported to the surface by hand to ensure that they were held upright. Pipe caps were secured to the pipe sections, and the sample code was written on the pipe section. All samples were marked with arrows designating the bottom and top of the sample, date collected, and sample designation. Sample codes were recorded in laboratory notebooks.

In the field and during transport to the laboratory, samples were kept frozen in ice chests containing dry ice. In the laboratory, they were stored in a freezer at $-20^{\circ} \mathrm{C}$. 
APPENDIX C

ANALYTICAL METHODS 


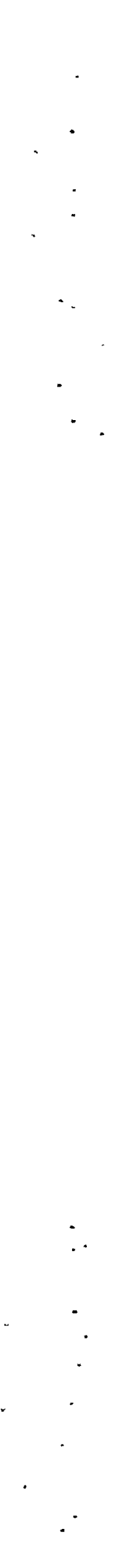


APPENDIX C

ANALYTICAL METHODS

\section{SEDIMENT SUBSAMPLING}

Sediment cores were subsampled by immersing the frozen core and casing in hot tap water for 15 minutes. This procedure permitted the core to be pushed from the casing while frozen. The core was then cut into two sections ( 2 in. each) using a diamond-tipped circular saw. Each section was then cut in half to provide duplicates. For each analysis, one of the duplicates of the top half was thawed, mixed, and a $100-g$ subsample was taken from it. The bottom half of each section and the duplicate portion of the top section were archived (stored in freezer) for possible future chemical analysis.

Extraction and Cleanup of Sediments

The procedures used to extract and concentrate PCBs, and to remove interfering material, are summarized in the flow diagram in Figure C.1.

\section{Sediment Extraction}

A $100-g$ sample of wet sediment was weighed into a $200-\mathrm{mL}$ glass centrifuge bottle, stirred with methanol $(50 \mathrm{~mL})$, and centrifuged at $163 \times$ gravity (1000 rpm) for 10 minutes. The methanol supernatant was removed and saved. The methanol wash was repeated, the supernatants combined, and poured through glass wool to remove any mineral residue. The glass wool was rinsed with an additional $10 \mathrm{~mL}$ methanol, which was combined with the methanol supernatant. Benzene $(2 \mathrm{~mL})$ was added to ensure that the PCBs in the supernatant stayed in solution. The methanol solution was then set aside.

The methanol-washed sediment was transferred to a weighed Soxhlet thimble (medium frit) and extracted in a Soxhlet apparatus for 48 hours with a mixture of $180 \mathrm{~mL}$ benzene and $120 \mathrm{~mL}$ methanol. The Soxhlet cup was removed, allowed to stand in the hood for 24 hours, then dried further in a forced-air oven at $110^{\circ} \mathrm{C}$, and weighed to obtain the weight of the dry sediment. 


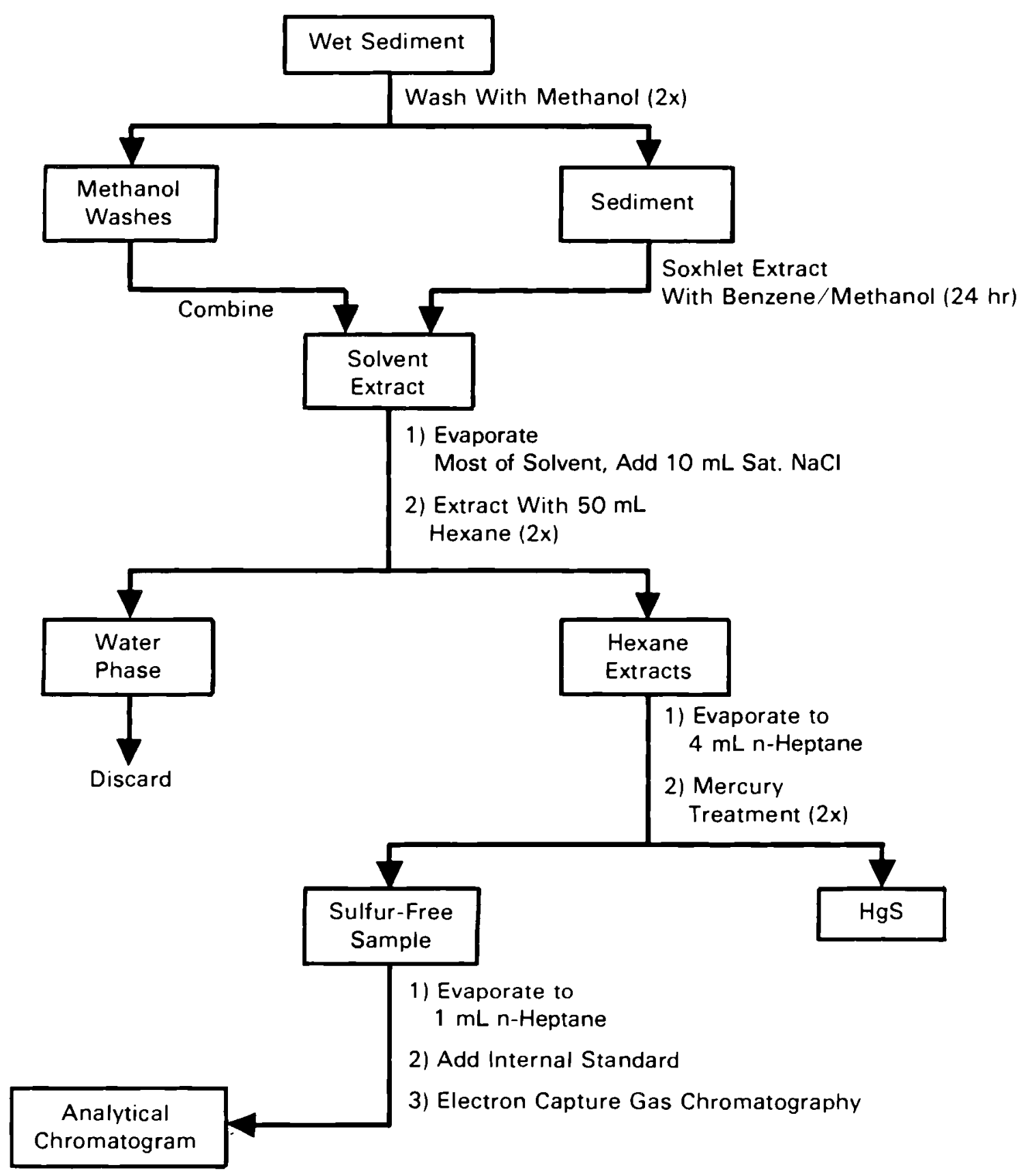

FIGURE C.1. Analytical Scheme for Determination of PCBs in Sediments 
The benzene-methanol extract was poured through glass wool to remove any mineral particles. The wool was rinsed with benzene $(10 \mathrm{~mL})$, the rinse was combined with the extract, and the extract was concentrated by rotary evaporator to about $20 \mathrm{~mL}$. The methanol supernatant from above were added to this concentrate, using three $5-\mathrm{mL}$ washes of hexane to transfer. Again, the extract was concentrated to approximately $20 \mathrm{~mL}$. Then, $4 \mathrm{~mL} n$-heptane was added, and evaporation continued to $4 \mathrm{~mL}$ organic phase. The heptane addition ( $4 \mathrm{~mL}$ ) and evaporation step was repeated again to ensure removal of methanol.

The solvent concentrate was transferred to a $250-\mathrm{mL}$ separatory funnel with $50 \mathrm{~mL}$ hexane. Saturated aqueous $\mathrm{NaCl}$ (10 $\mathrm{mL}$ ) was added, the funnel was shaken for 1 minute, and the hexane was removed. The hexane extraction was repeated, and extracts were combined and dried over anhydrous $\mathrm{Na}_{2} \mathrm{SO}_{4}$. The dry extract was reduced to about $6 \mathrm{~mL}$ with the roto-evaporator, transferred to 5-mL soluvials, and volume reduced again to $4 \mathrm{~mL}$ under dry nitrogen.

\section{Sulfur Removal}

Elemental sulfur was a major contaminant in almost all samples analyzed. It was necessary to remove sulfur from the samples because it co-chromatographs with PCBS, and it exhibits a significant response in the electron capture detector used for the analys is of PCBs.

Metallic mercury (USP) was used to remove sulfur according to the procedure of Caragay and Levens (1979). Prior to use, the mercury was treated with concentrated nitric acid, then washed with distilled water followed by methanol, and dried under a stream of nitrogen. Six small drops (ca. $5 \mathrm{~g}$ ) of mercury were added to each sample (in soluvials, after extraction and concentration). Then the samples were vigorously agitated in a test tube vortex mixer for 20 minutes. The treated heptane solution was then removed quantitatively to a new soluvial and the treatment repeated. This procedure was sufficient to remove all interfering sulfur. The sample was ready for further isolation of PCBs, employing silica gel chromatography.

\section{Silica Gel Chromatography}

The mercury-treated samples were subjected to chromatography over silica gel to further isolate PCBs, using a procedure reported by Warner (1976). The 
procedure has been used in our laboratories for some time as a general tool for cleanup of aromatic organics in environmental samples.

Fifteen grams of 100-200-mesh silica gel, activated at a temperature of $150^{\circ} \mathrm{C}$ overnight, was slurry-packed into a $25 \times 1.25-\mathrm{cm}$ glass column using hexane. The column was cleaned by passing, successively, $30 \mathrm{~mL}$ methylene chloride and $40 \mathrm{~mL}$ of hexane through the column. The sample, reduced to $1 \mathrm{~mL}$ $\mathrm{n}$-heptane, was placed on the column, and eluted first with $40 \mathrm{~mL}$ of hexane, then $86 \mathrm{~mL}$ methylene chloride. The methylene chloride fraction containing the PCBs was reduced in volume in two steps. First, the rotary evaporator was used. Then, $n$-heptane was added, and remaining solvent was removed under a stream of nitrogen. The methylene chloride concentrate was exchanged into n-heptane. Final volume was $1 \mathrm{~mL}$.

Gas Chromatographic Analysis

Prior to analysis by gas chromatography, $10 \mu \mathrm{L}$ of an internal standard was added by syringe to the sample contained in $1 \mathrm{~mL} n$-heptane. The internal standard was 1-bromonaphthalene, prepared by adding $50 \mu \mathrm{L}$ to $50 \mathrm{~mL}$-heptane, followed by a further 1:25 dilution in n-heptane. After shaking, the sample was ready for analysis. Aroclor standards used for comparison were al so treated with internal standard prior to chromatography. Analysis was performed on a Hewlett-Packard Model 5840 gas chromatograph (Hewlett-Packard Co., Avondale Division, Avondale, Pennsylvania). A capillary injector was utilized, in the splitless mode. The capillary chromatography column used for separation was a $60-\mathrm{m} \times 0.25-\mathrm{mm} \mathrm{DB}-1$. Conditions were as follows: helium flow, $2 \mathrm{~mL} / \mathrm{min}$; initial temperature, $70^{\circ} \mathrm{C}$; hold for 4 minutes, then $5^{\circ} /$ minute to $250^{\circ} \mathrm{C}$, and hold for 15 minutes. Detection was by electron capture detector supplied with $40 \mathrm{~mL} /$ minute $10 \%$ methane in argon.

Because of interference by other electron-capturing peaks, quantification of PCBs by integrating all peaks in the region of PCB retention time was not appropriate. We found that good results could be obtained by selecting nine prominent peaks and comparing their total area to the corresponding nine peaks in an Aroclor 1260 standard. The peaks selected for quantification are shown in Figure 6. At times, interfering peaks would mask the peaks selected for 
quantification. In that case, quantification was based on those peaks not masked; they were compared with the corresponding peaks in the standard.

Efficiency of recovery was checked by spiking $3.12 \mu \mathrm{g}$ Aroclor 1260 into 100-g sediment samples known to contain elemental sulfur, but not containing appreciable quantities of PCBs. Recovery from triplicate spiked samples was $3.44 \pm 0.01 \mu \mathrm{g}$, or $110 \%$. 
Caragay, A. B., and P. L. Levens. 1979. Evaluation of Protocols for Pesticides and PCBs in Raw Wastewater. EPA-600/2-79-1, 66, U.S. Environmental Protection Agency, Washington, D.C.

Warner, J. S. 1976. "Determination of Aliphatic and Aromatic Hydrocarbons in Marine Organisms." Anal. Chem. 48:578-83. 
APPENDIX D

STATISTICAL METHODS 


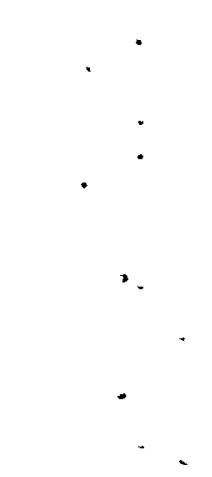


APPENDIX D

\section{STATISTICAL METHODS}

SAMPLING DESIGN

The objective of this study was to estimate the spatial pattern of PCB concentrations in the sediment of Gable Mountain Pond. Therefore, sediment samples were collected on a uniform grid: the sampling design best suited for producing a contour map of sediment concentrations. Kriging, a statistical technique described later in this appendix, was used to estimate concentration contours.

Three groups of five replicate samples were taken in each of three areas in the pond: in the middle of the pond, near the shore, and between these two. These replicates were used to estimate the sampling variance in different areas of the pond. The three areas in particular were chosen because it is likely that the sediment structure of the pond varies with increasing distance from the shoreline. The sediment near the shore contained organic material from the aquatic vegetation that grows on the pond perimeter. Areas away from the shoreline contained less organic matter.

Grab samples of sediment in the pond vegetation were taken at the north and south ends of each of the 15 main transects. These could not be analyzed statistically along with the grid sediment cores because of the differences in sampling techniques. Three groups of grab samples, five samples in each group, were taken at randomly selected locations in the cattails to estimate the sampling variance in this habitat.

A small part of the pond, at approximately the northeastern end, is separated from the main body of water by a road. This area was far too small to be sampled using a 150-ft grid. Therefore, five sediment cores were taken at randomly selected locations in this smaller portion of the pond. Because of the difficulties in locating randomly generated points in this section of the pond, a judgment sampling scheme was used to locate the sampling sites (Eberhardt and Gilbert 1975). 


\section{$\underline{\text { Kriging }}$}

Kriging was used to estimate the contour maps of PCB concentrations and water depth in Gable Mountain Pond. A weighted moving-average technique that calculates point estimates or block averages over a specified grid, kriging was developed for use in the mining industry, primarily in Europe and South Africa (Clark 1982). Values at points or areas between actual observations are estimated by a weighted average of the surrounding observations. The derivation of the weights takes into account the proximity of the observation to the point or area of interest, the structure of the observations ( $i . e .$, the relationship of the squared differences between pairs of observations and the intervening distances between them) and any systematic trend or drift in the observations. Additionally, kriging estimates the variance and confidence intervals for the contours. 
Clark, I. 1982. Practical Geostatistics. Applied Science Publishers Ltd., London.

Eberhardt, L. L., and R. 0. Gilbert. 1975. "Biostatistical Aspects." Part 8 in Environmental Impact Monitoring of Nuclear Power Plants: Source Book of Monitoring Methods. Vol . 2, AIF/NESP-004, Prepared by Battelle, Pacific Northwest Laboratories and Columbus Laboratories, for Atomic Industrial Forum, Inc., New York. 


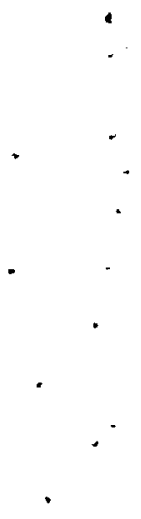




\section{DISTRIBUTION}

No. of

Copies

OFFSITE

30 DOE Technical Information Center

\section{ONSITE}

5 DOE Richland Operations Office

R. E. Austin

D. R. Elle

R. E. Gerton

J. J. Sutey

P. J. Krupin

2 Rockwell Hanford Operations

W. F. Heine

R. E. Wheeler

63 Pacific Northwest Laboratory

R. M. Bean

P. E. Bramson

J. P. Corley

D. W. Dragnich
No. of

Copies

P. A. Eddy

C. E. Elderkin

R. E. Fitzner

J. S. Fruchter

H. A. Haerer

J. M. Hales

P. C. Hays

S. F. Liebetrau

J. L. McElroy

T. J. McLaughlin

D. A. Neitzel

T. L. Page

L. S. Prater

K. R. Price

L. A. Prohammer

W. H. Rickard

R. G. Riley (29)

J. V. Robinson

D. J. Sommer

B. L. Steelman

J. A. Stott lemyre

J. M. Thomas

P. Van Voris

R. E. Wildung

Publishing Coordination (2)

Technical Information (5) 


\section{-}

1

1

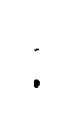

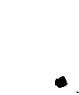
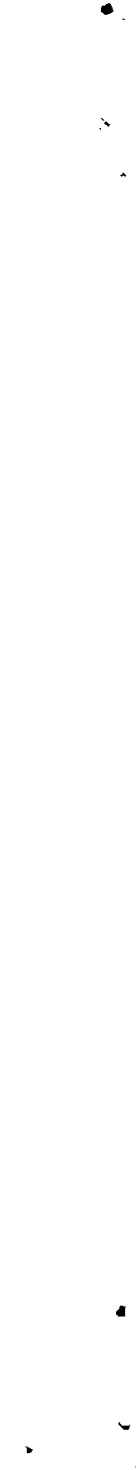

. 